\title{
EL DEBATE DE LA EUTANASIA Y EL SUICIDIO ASISTIDO EN PERSPECTIVA COMPARADA. GARANTÍAS DE PROCEDIMIENTO A TENER EN CUENTA ANTE SU EVENTUAL DESPENALIZACIÓN EN ESPAÑA ${ }^{1}$
}

\author{
POR \\ FERNANDO REY MARTÍNEZ \\ Profesor Titular de Derecho Constitucional \\ (Universidad de Valladolid) \\ Catedrático habilitado de Derecho Constitucional
}

\section{INTRODUCCIÓN}

En materia de derechos fundamentales la interpretación comparada, la mirada por encima de las fronteras, es un recurso imprescindible. Así ocurre, de manera particular, dado su controvertido carácter, con la regulación de la

${ }^{1}$ El presente trabajo es, en líneas generales, un capítulo de la monografía que, bajo el título "Constitución y buena muerte. Eutanasia, suicidio y derechos fundamentales", presenté el 11 de junio de 2007 en la Universidad de Murcia, al segundo ejercicio de las pruebas de habilitación para Catedrático de Universidad como «trabajo original e inédito de investigación» (art. 10.5 R.D. 774/2002, de 26 de julio, por el que se regula el sistema de habilitación nacional para el acceso a Cuerpos de Funcionarios Docentes Universitarios y el régimen de los concursos de acceso respectivos). 
eutanasia y el suicidio asistido en el extranjero. Una primera observación es que son escasos los ordenamientos que permiten tales conductas y todos ellos son del primer mundo, lo que, sin duda, no es casual: el problema se plantea de forma aguda allí donde hay mayor esperanza de vida y mayores medios técnicos para prolongarla, así como una concepción social mayoritaria de la vida más secularizada, esto es, menos condicionada por las convicciones religiosas dominantes, coincidentes en subrayar el carácter sagrado o intangible de la vida humana ${ }^{2}$. El contexto fáctico del problema de la eutanasia es el surgimiento de un nuevo poder, con riesgo de desbordamiento y abuso, frente al que los derechos fundamentales deben reaccionar para asegurar a las personas un ámbito de libertad, el poder emergente de la tecnología médica en relación con el final de la existencia humana, que, además, se halla «medicalizado».

No es, por ello, fruto del azar que el tema de la eutanasia no esté, al menos por el momento, en la agenda del constitucionalismo de los países periféricos. La única excepción significativa procede de Colombia. Ciertamente, tampoco allí se reconoce la licitud de la eutanasia activa o del suicidio asistido, pero se tipifican en su Código Penal expresamente como formas atenuadas de homicidio y de inducción y auxilio al suicidio y, sobre todo, la Sentencia de su Corte Constitucional C-239/97, de 20 de mayo de 1997 (ponente: Dr. Carlos Gaviria), ha deducido de la Constitución de 1991 la exclusión de antijuridicidad de la conducta del médico que, bajo ciertas condiciones, sobre todo la del consentimiento de la víctima, pusiera fin a la vida de un enfermo en fase terminal. Esta Sentencia, de gran impacto en el país, como cabe imaginar, pero también en la región (no en vano las decisiones de la Corte Constitucional colombiana tienen bien ganada fama de calidad técnica), no deja de resultar curiosa por varios motivos. Ante todo porque el recurso de la que trae causa se dirige contra el precepto del Código Penal que atenúa el «homicidio por piedad» por considerar que «desconoce» el derecho a la vida declarado «inviolable» por el art. 11 de la Constitución porque «la levedad de la sanción constituye una autorización para matar», y, sin embargo, la Sentencia, no sólo declara conforme a Constitución el precepto penal mencionado, sino que va mucho más allá y encuentra en el texto constitucional la regla de que la conducta del médico que pone fin a la vida de un enfermo en fase terminal a petición de éste no es antijurídica. En otras palabras, el recurrente pedía que se considerara inconstitucional la atenuación de la eutanasia respecto del tipo común de homicidio y lo que final-

2 Todos los países son, además, de tradición cristiana, el credo religioso más secularizado, sobre todo en su modalidad protestante. 
mente consiguió es que se declarara inconstitucional la sanción penal misma del médico que practicara la eutanasia ${ }^{3}$.

Así pues, la primera constatación es que casi todos los países prohíben penalmente la eutanasia y ni siquiera la regulan específicamente, sino dentro del marco más amplio del castigo de las conductas de colaboración en el suicidio ajeno o del homicidio a petición ${ }^{4}$. Carmen Tomás-Valiente distingue algunos ordenamientos en los que son lícitas ciertas conductas de colaboración en el suicidio en contextos eutanásicos de modo muy limitado, como Alemania y Suiza, de otros en los que existe una despenalización de la eutanasia, aunque sea parcial, como Bélgica y, sobre todo, Holanda. En Alemania es impune la colaboración no imprescindible al suicidio ajeno, así como la cooperación necesaria e incluso la inducción (la única conducta que puede sancionarse, según el art. 216 del Código Penal, es el homicidio a petición, esto es, el caso en el que el tercero no se limita a ayudar a otra persona a quitarse la vida, sino que es él quien directamente la pone $\mathrm{fin}^{5}$ ), pero ni la sociedad ni la profesión médica alemanas perciben que existe una despenalización del suicidio asistido, ni es práctica corriente ${ }^{6}$. En Suiza el homicidio a petición también se castiga penalmente (art. 114 del Código Penal), pero la cooperación al suicidio sólo se sanciona cuando obedez-

3 La Sentencia ordena al legislador que establezca una «regulación legal muy estricta» del «homicidio por piedad», que incluya diversas orientaciones que la Corte precisa, advirtiendo que en tanto lo haga, todo homicidio por piedad debe ser investigado para determinar si es o no antijurídico en los términos concretados por la Sentencia. El legislador colombiano, sin embargo, no ha llevado a cabo una regulación en el sentido demandado por la mayoría de las Corte, sino que ha mantenido, en líneas generales, el régimen penal analizado por ella. La licitud (parcial) de la eutanasia tiene pues, en Colombia, como fundamento exclusivo esta decisión de la Corte, que es la única en el mundo que reconoce la práctica de la eutanasia (bajo ciertas condiciones) como un auténtico derecho fundamental "a morir con dignidad», pero el legislador no se ha dado aún por enterado.

${ }^{4}$ C. TOMÁs-VAliente: «Posibilidades de regulación de la eutanasia solicitada», Documento de trabajo, Fundación Alternativas, Madrid, 2005, p. 15.

${ }^{5}$ De modo que, como ejemplifica TOMÁs-VALIENTE (ibidem, p. 16), no sería delito poner a disposición de un suicida el barbitúrico que luego éste ingerirá por sí mismo, pero sí suministrarle directamente una inyección letal. Ver también: JAKOBS (Suicidio, eutanasia y derecho penal, Tirant lo Blanch, Valencia, 1999, p. 25).

6 Tomás-Valiente, ibidem, 16. Hay que recordar, con Kaufmann ( «Relativización de la protección jurídica de la vida?», en C.P.C., n. ${ }^{\circ} 31,1987$, p. 46), que la discusión sobre la eutanasia se ve dificultada en Alemania por la "conmoción» que provocó el "programa de eutanasia» de la dictadura hitleriana, que sigue "repercutiendo hasta nuestros días». De igual modo: RoxIN (Eutanasia y suicidio. Cuestiones dogmáticas y de política criminal, Comares, Granada, 2001, p. 33). De acercarse «con pies de plomo» en Alemania al problema de la protección de la vida habla HUFEN («In dubio pro dignitate. Selbstbestimmung und Grundrechtsschutz am Ende des Lebens», en Neue Juristische Wochenschrift, 2001, p. 850). 
ca a «motivos egoístas»; y esta regulación tan «imperfecta» por «insegura», ha abierto, sin embargo, y a diferencia de lo que sucede en Alemania, "un hueco de licitud de ciertas prácticas eutanásicas», fomentadas por diversas asociaciones, algunas de las cuales promueven el turismo eutanásico ${ }^{7}$.

En el Estado norteamericano de Oregón existe una regulación específica del suicidio asistido por médico. Se trata de una experiencia original en el Derecho comparado, de gran interés, por lo que será objeto de análisis más adelante. Es original, incluso, respecto del resto de la Unión, donde eutanasia y suicidio asistido son conductas castigadas por el Derecho penal.

Los ordenamientos que explícitamente han despenalizado ciertas conductas eutanásicas han sido Holanda y, más recientemente, Bélgica. Por supuesto, merecen también un examen atento. En estos países el camino recorrido hasta la despenalización (parcial) de la eutanasia ha sido idéntico: la condena penal inicial tout court se pone en cuestión primero por ciertas decisiones judiciales que versaban sobre casos difíciles, altamente publicitados, y más tarde es el legislador el que hace suyos los criterios de despenalización judicialmente acuñados.

Antes de pasar a identificar los rasgos más importantes de régimen de los ordenamientos de Holanda y de Oregón en este punto, conviene dejar constancia de que en el capítulo de experiencias comparadas también es frecuente invocar el ejemplo del primer reconocimiento legislativo en la historia de la eutanasia y el suicidio asistido, el del Territorio Norte de Australia, cuyo Parlamento aprobó el 16 de junio de 1995 la Ley de Derechos de los Enfermos Terminales, ampliamente despenalizadora, pero que fue derogada por el Parlamento federal australiano en menos de un $a_{n} o^{8}$ (su impronta, sin embargo, se deja sentir en la posterior regulación de Oregón). La eutanasia podía ser solicitada por un pa-

7 TOMÁs-VAliENTE, ibidem, 17. Las conductas son lícitas siempre que «consistan en colaborar en el suicidio del enfermo y no lleguen a franquear el límite de que sea el tercero quien le produzca la muerte». Es conocida la actividad de asociaciones pro-eutanasia que facilitan ayuda a enfermos que desean morir, como Dignitas ó Exit-Deutsche Schweiz; la primera presta ayuda también a extranjeros no residentes en Suiza, de modo que ha generado un cierto turismo eutanásico.

${ }^{8}$ La Euthanasia Law Act fue aprobada el 27 de marzo de 1997; prohibe a las Asambleas legislativas de los Estados dictar leyes que permitan cualquier forma de homicidio intencional denominado eutanasia o de asistencia a cualquier persona para poner fin a su vida. La Ley del Northern Territory (un Estado, por cierto, de escasa población, menos de doscientas mil personas, el 1\% del total de la población australiana) fue, en el periodo que estuvo vigente, sometida a examen por la Supreme Court a impugnación de la Asociación Médica australiana, que no estimó su inconstitucionalidad ni su extralimitación respecto de los poderes de la Federación, y también hubo un intento de derogación en la Asamblea legislativa que no prosperó (por 14 votos a 11). A cuatro personas se les aplicó la eutanasia, todas ellas a manos del mismo médico. Ver: FLEMING, «Death, Dying and Eutanasia: Australia versus the Northern Territory», Issues in Law and Medicine, vol. 15, 2000, pp. 299 y ss. 
ciente mayor de 18 años, competente para tomar esa decisión (art. 7.1) que en el curso de una enfermedad terminal, sufriera dolores y/o angustia de manera inaceptable para él» (art. 4) y había de practicarse por médico, aunque debía haberse consultado antes con un segundo médico (con conocimientos acreditados de psicología que le facultara para certificar que el paciente no sufría una depresión clínica tratable — art. 7.1.c-). Por «asistencia» médica se entendía «el prescribir, el preparar, el proporcionar una sustancia letal al paciente para la autoadministración o el suministrar una sustancia letal al paciente» (art. 3). El enfermo debía ser informado de su diagnóstico y posibilidades de tratamiento, incluyendo cuidados paliativos (art. 7.1.e); debía pedir la eutanasia por escrito ("certificado de petición`»), que no podía ser firmado hasta que hubieran transcurrido siete días desde la declaración del deseo de morir del paciente (art. 7.1.i). Debían transcurrir al menos 48 horas entre la firma del certificado de petición y la "asistencia», sin que el paciente hubiera dado al médico indicaciones contrarias al deseo de poner fin a la propia vida (art. 7.1.n). El médico no debía dar curso a la petición de morir «si, según su juicio, existen cuidados paliativos razonablemente disponibles para aliviar el dolor y el sufrimiento a un nivel aceptable para el paciente»; pero, «si más tarde los cuidados paliativos cesan de mitigar el dolor o el sufrimiento del paciente», el médico, si era nuevamente requerido, debía proceder a asistir al paciente (art. 8).

El procedimiento de control era ex post (arts. 12 a 14): el médico que hubiera practicado la eutanasia debía incluir una serie de documentos (certificado de petición, certificación de la segunda opinión médica, etc.) en la historia clínica del paciente (obligación cuyo incumplimiento conllevaría una pena de multa o de prisión de hasta dos años); y debía remitir estos documentos tan pronto como fuera posible tras la muerte del paciente al Ministerio Público (Coroner), el cual tenía a su vez que comunicar al Attorney General, con una periodicidad anual, el número de pacientes fallecidos en aplicación de la Ley, dato que el Fiscal General tenía que poner en conocimiento de la Asamblea General ${ }^{10}$. La

9 Este certificado debía ser firmado por el paciente y, en la presencia suya y del médico asistente, por otro médico que, después de haber discutido el caso con aquéllos, estuviera razonablemente convencido que la petición era regular, el paciente competente para tomar la decisión y su decisión de poner fin a su vida había sido adoptada libre y conscientemente (art. 7.1.k). Si el enfermo estaba consciente, pero no podía materialmente firmar la petición, lo podría hacer otra persona mayor de 18 años a su petición (que no fuera el médico que le atendía ni cualquier persona que pudiera obtener, directa o indirectamente, una ventaja económica o de otro tipo de la muerte del enfermo (art. 9.1).

${ }^{10}$ Es decir, no parecía existir un procedimiento específico de control, sino que la práctica eutanásica "quedaba sujeta a los procedimientos ordinarios aplicables a cualquier otro hecho susceptible de ser constitutivo de delito» TOMÁs-VAlIENTE, ibidem, p. 24. 
Ley reconocía un derecho de objeción de conciencia a los médicos para evitar participar en procedimientos de este tipo (art. 5). Expresamente se reconocía la impunidad penal, civil o disciplinaria de la conducta del médico en estos casos (art. 16). Se sancionaba con la pena de cuatro años de reclusión o multa, así como con la pérdida de cualquier ventaja que pudiera obtener de la muerte del enfermo, a quien indujere, con «engaño o presiones indebidas» a la suscripción del certificado de petición (art. 11).

También con carácter previo, me gustaría llamar la atención, por último, sobre la debilidad del argumento, por otro lado frecuentemente utilizado en el debate sobre la eutanasia, que ve las experiencias holandesa, belga, etc., no como una excepción en el panorama internacional (que es, en realidad, lo que son), sino como una suerte de ideal o modelo a seguir por todos en el futuro. No es que no haya consenso internacional sobre el problema de la eutanasia; lo hay, y es claramente contrario a su legalización. En Estados Unidos la cuestión se puso de moda a mediados de los noventa, pero ahora, aunque conflictiva, parece tener un volumen de ruido menor. Este país, junto con la breve experiencia australiana, demuestra que, respecto de la despenalización de la eutanasia, hay «avances» pero también «retrocesos» ya que algunas decisiones judiciales inicialmente favorables a la eutanasia fueron más tarde revertidas por tribunales superiores.

Evidentemente, la prohibición de la eutanasia y/o del suicidio asistido plantea problemas en algunos casos concretos. Y, por otro lado, el avance del principio de autonomía del paciente y del reconocimiento de sus derechos, también en el proceso del fin de su vida, ha parecido alentar durante un tiempo la idea de la crisis del modelo vigente de prohibición. Pero esta idea es, en lo que se refiere a la admisión jurídica de la licitud de la eutanasia, nugatoria. Holanda, Oregón, Bélgica, etc. no son, de hecho, dentro del panorama mundial el modelo, sino la excepción ${ }^{11}$.

En definitiva, me parece más interesada (ideológicamente) que interesante (intelectualmente) la tesis de que las legislaciones que están reconociendo la licitud de ciertas formas de eutanasia son «un modelo a seguir», una especie de futuro inevitable ${ }^{12}$; la cuestión es bastante más compleja. Pudieran convertirse en

${ }^{11}$ Recuérdese, por ejemplo, que la Asamblea Parlamentaria del Consejo de Europa rechazó el 27 de abril de 2005 por 128 votos contra 56 un proyecto de resolución que pedía legalizar la eutanasia en el continente europeo. Se mantiene, pues, el vigor de la Recomendación 1418 (1999), cuyo párrafo noveno reconoce que el deseo de un enfermo terminal de morir «nunca puede constituir una demanda legal para morir a manos de otra persona» y que tampoco "puede por sí mismo constituir una justificación legal para evitar las acciones penales derivadas de la causación de la muerte».

${ }_{12}$ Así, por ejemplo, lo sostiene, entre nosotros, M. J. PAREjo (La Eutanasia, ¿un Derecho?, Thomson \& Aranzadi, Navarra, 2005, p. 4). 
un ejemplo, pero también en lo contrario, en una pauta a no seguir. Ni siquiera los «modelos» de legalización disponibles, como veremos, son totalmente homogéneos entre sí, sino que guardan significativas diferencias.

\section{DESPENALIZACIÓN (PARCIAL) DE LA EUTANASIA: LOS CASOS DE HOLANDA Y BÉLGICA.}

Holanda es uno de los pocos países en el mundo donde, sobre todo a partir de los ochentas, se aplica con regularidad un modelo de eutanasia activa directa y, por ello, constituye un «natural foco de atención» de todos aquellos que pretender implementar un régimen de este tipo en otro lugar ${ }^{13}$. «Korthals/Borst» de «Verificación de la terminación de la Vida a Petición Propia y Auxilio al Suicidio", que entra en vigor el 1 de abril de 2002, viene a codificar una dilatada y constante jurisprudencia a favor de la despenalización, bajo ciertas condiciones, de la eutanasia. La cuestión se plantea de modo significativo en los Países Bajos a partir del caso Postma $\left(1973^{14}\right)$ : una médica que puso fin a la vida de su madre de 78 años de edad a petición de ésta fue acusada de homicidio y finalmente condenada condicionalmente a una semana de prisión ${ }^{15}$.

13 GORSUCH («The legalization of assisted-suicide and the Law of unintended consequences: a review of the Dutch and Oregon experiments and leading utilitarian arguments for legal change», en Wisconsin Law Review, 2004, p. 1353). El sistema belga, en efecto, se construye a su imagen. La Ley.

14 Aunque hay antecedentes de interés, que recuerda Mora Molina en su documentado estudio («Despenalización de la eutanasia en los Países Bajos. El Proyecto de Ley Korthals/Borst», en Derechos y Libertades. Revista del Instituto Bartolomé de las Casas, enero 2002, n. ${ }^{\circ} 11$, pp. 538 y ss.): Ya en 1970 se creó la primera Comisión estatal para el estudio, análisis y proyecto de solución al fenómeno de la eutanasia (en los ochentas hubo otra, y en los noventas otra, la Comisión Remmelink). En 1977 se publicó el informe de esta Comisión, favorable a una solución legal que regulara la eutanasia. Se recuerda también la influyente obra del médico Jan Hendrick van der Berg, de 1969, titulada «Poder Médico y Ética Médica», recomendando a los médicos «acabar con la vida de sus pacientes si el poder de la tecnología médica les hiciera sufrir, vegetar o prolongar injustificadamente su agonía». Tras la Sentencia Postma se crea la Asociación Holandesa para la Aceptación de la Eutanasia Voluntaria.

${ }^{15}$ Ver: Mora Molina, ibidem, pp. 554 y ss. La Sentencia es del Tribunal de Distrito de Leeuwarden. La madre de la médica Geertruida Postma había sufrido una grave hemorragia cerebral, estaba paralizada en parte, tenía problemas de habla, estaba sorda, repetidamente había mostrado sus deseos de morir y había fracasado en un intento de suicidio. Su hija le administró una inyección letal de morfina y en el proceso sostuvo que había obrado de la forma correcta con el único error de no haberlo hecho antes. El Tribunal estableció ciertas condiciones para la práctica impune de la eutanasia, que fueron influyentes más tarde: $\left(1 .^{\circ}\right)$ que el paciente fuese un enfermo incurable, 
La Sentencia Wertheim ${ }^{16}$ (1981) reprodujo los criterios de impunibilidad de la eutanasia enunciados en el caso Postma, añadiendo algunos más ${ }^{17}$. En 1984 se produjo otro asunto de gran impacto sobre la opinión pública, el caso Schoonheim, que afectaba a una mujer de 93 años que estaba enferma e inconciente, María Barendregt, pero que, al recuperar la consciencia, solicitó y obtuvo de su médico una eutanasia activa directa. El conflicto llegó al Tribunal Supremo del país, que, en su sentencia de 27 de noviembre de 1984, aprovechó la disputa para identificar una excepción a la expresa prohibición penal de la eutanasia y del suicidio asistido ${ }^{18}$, apreciando no tanto la autonomía del paciente, cuanto un caso de "fuerza mayor ${ }^{19}$ ", concretamente un conflicto de deberes del médico (entre los cuidados debidos al paciente y la obediencia a la ley), por lo que su conducta estaría justificada por su valoración acerca de la carencia de calidad de vida de su paciente ${ }^{20}$. En 1986 se produjo el caso Groningen, que permitió consolidar los criterios de validez de la eutanasia de las decisiones judiciales anteriores ${ }^{21}$. En 1988, la Real Sociedad para la promoción de la Medicina estableció ciertos cri-

experimentase un sufrimiento insoportable y su muerte fuera inminente; $\left(2 .^{a}\right)$ que el paciente pidiese la terminación de su vida y $\left(3{ }^{a}\right)$ que el facultativo de tal paciente llevase a cabo la eutanasia y que procediese antes a consultar a otro colega.

${ }_{16}$ El señor Wertheim ayudó a morir a su mujer, de sesenta y siete años de edad, que estaba convencida de padecer un cáncer (aunque luego la autopsia demostró que no era verdad).

17 Son los llamados «criterios de Rotterdam» (pues el tribunal que falló el caso era de esta ciudad). Ver: Mora Molina (ibidem, p. 556). La asistencia al suicidio es admisible, además de si se respetan los criterios del caso Postma, si la decisión no la toma una sola persona (que debe ser médico en todo caso) y si en la ayuda se adopta un cuidado extremo (por ejemplo, de consulta con sus colegas, etc.).

18 Gorsuch, ibidem, p. 1355. El art. 293 del Código Penal holandés prohibía causar la muerte de otra persona incluso a petición expresa de ésta y el art. 294 sancionaba «incitar intencionalmente a otro a suicidarse, asistirle en el suicidio, o procurarle los medios para ello».

$19 \mathrm{El}$ art. 40 del Código Penal holandés configura como exonerante la «fuerza mayor»: «El que cometiese un crimen siendo compelido a actuar de ese modo por fuerza mayor, quedará exento de pena».

20 «De acuerdo con las normas éticas de la medicina, y con la profesionalidad que se debe presumir que posee, el médico contrastó los deberes e intereses que, en el caso, estaban en conflicto e hizo una elección que, objetivamente considerada, y teniendo en cuenta las específicas circunstancias del caso, estaba justificada». KEOWN («La eutanasia en Holanda», en La Eutanasia examinada. Perspectivas éticas, clínicas y legales. Fondo de Cultura Económica, México, 2004, p. 350) critica esta sentencia porque «no explica el por qué el deber del médico de aliviar el sufrimiento tiene preeminencia sobre su deber de no matar» y porque «el tribunal parece haber delegado en la opinión médica el poder de determinar las circunstancias en las que el homicidio puede justificar la defensa por necesidad».

${ }^{21}$ Una médica practicó la eutanasia a una paciente de 73 años que padecía una esclerosis múltiple y a continuación informó al Fiscal. Para las circunstancias del caso, ver MorA MOLINA, ibidem, pp. 561 y ss. 
terios para aplicar el suicidio asistido o la eutanasia de acuerdo con la nueva interpretación judicial y el Ministro de Justicia declaró que los médicos que siguieran estas pautas no serían perseguidos ${ }^{22}$.

En 1994, el Tribunal Supremo, en el famoso caso Chabot, apreció una causa de justificación en la muerte de una mujer de 50 años a consecuencia de la medicación letal que la proporcionó su psiquiatra ${ }^{23}$. El Supremo consideró que para que una petición de suicidio asistido o de eutanasia pudiera estimarse justificada por un estado de necesidad (cuando tuviese que escoger entre la obligación de conservar la vida y el deber de hacer todo lo posible para aliviar el sufrimiento insoportable sin perspectivas de mejora de un paciente confiado a su cuidado), no era necesario que el sufrimiento fuera físico o que el enfermo estuviera en una fase terminal. De modo que el sufrimiento puramente psicológico podría habilitar a un paciente para solicitar la eutanasia y que los enfermos psiquiátricos son capaces de alcanzar decisiones autónomas, tanto como los que padecen una enfermedad física ${ }^{24}$. La Sentencia Chabot supuso en su momento, por tanto, una extensión de las causas de justificación de la eutanasia, una ampliación de los «casos clásicos de eutanasia ${ }^{25}$ ». El último intento de extensión, que no ha tenido éxito ante el Tribunal Supremo (pero sí en algunos tribunales inferiores) ha sido el de ampliar la causa de justificación de la eutanasia a las personas que tengan «sufrimiento existencial» (superando el criterio del sufrimiento — físico o psíquico- insoportable y sin esperanzas de mejora). El caso Brongserma ${ }^{26}$,

22 «Guidelines for Euthanasia», en Issues Law \& Medicine, n. 3, p. 429. Bajo esta Guía, la petición de ayuda a morir tenía que ser voluntaria, seria y persistente; el paciente tenía que tener un sufrimiento inaceptable y el médico tenía que solicitar una segunda opinión médica.

${ }^{23}$ Un hijo de la señora Boomsma se había suicidado en 1986; en 1988 falleció su padre; en 1990 se divorció y otro hijo sufrió un accidente de tráfico, del que se iba recuperando cuando se le descubrió un cáncer, del que murió poco después; en 1991 la señora Boomsma se intentó suicidar sin éxito. Después de todos estos acontecimientos, el psiquiatra Dr. Chabot, tras examinarla y consultar el caso con otros médicos, concluyó que el sufrimiento psicológico de su paciente era «insoportable» y que no tenía perspectivas de mejora. Siete semanas después de empezar a tratarla, el Dr. Chabot la suministró medicación letal y ella falleció media hora después.

${ }^{24}$ El Tribunal sostuvo, sin embargo, que el Dr. Chabot se equivocó en no propiciar una consulta directa de la señora Boomsma con los colegas a los que pidió opinión, pero no le impuso una sanción por ello.

25 DE VRIES, ob. cit., 379.

${ }^{26}$ Un médico ayudó a suicidarse a un anciano que no tenía enfermedad alguna pero que, a su juicio, padecía un sufrimiento insoportable e irreversible. El Sr. Brongersma, un ex -senador que había apoyado la legalización de la muerte a petición, había estado consultado a ese doctor desde 1986. En 1998 solicitó ayuda al médico para suicidarse dado su deterioro físico y la carencia de sentido de su existencia. De hecho, había intentado suicidarse en 1996. Otro médico confirmó que su deseo de morir era sincero y voluntario. 
fallado por el Supremo el 24 de diciembre de 2002, cierra la puerta a la eutanasia "no-médica», pero puede ser que sólo de momento. De hecho, el Tribunal inferior, de Haarlem, en su sentencia de 30 de octubre de 2000, había sostenido que una causa clínica no era necesaria para apreciar un sufrimiento en el paciente que justificara la ayuda a su suicidio o su propia muerte, aunque el Tribunal de Apelaciones de Ámsterdam revocara la sentencia ${ }^{27}$ y más tarde el Supremo también lo hiciera. La Sentencia del Supremo sostuvo que las cuestiones sobre la vida y el sufrimiento existencial caían fuera de la competencia profesional de un médico. Y, por consiguiente, cualquier deseo de morir inspirado por este tipo de sufrimiento, no es una petición que un médico pudiera cursar bajo el marco jurídico aplicable. Si lo hiciera, no estaría actuando como un médico y no podría estar protegido por el estado de necesidad. El Supremo concluyó que los problemas de la vida no son problemas médicos.

Con estas decisiones judiciales de fondo, tras diversos trabajos parlamentarios, y después de la todavía tímida Ley de 2 de diciembre de 1992 que, sin afectar al Código Penal, reformaba la Ley de Inhumaciones ${ }^{28}$, finalmente, se dicta La Ley de "Verificación de la terminación de la Vida a Petición Propia y Auxilio al Suicidio", que entra en vigor el 1 de abril de 2002, modifica los artículos 293 y 294 del Código Penal y presta cobertura jurídica legal a un conjunto de prácticas que habían sido validadas judicialmente hasta ese momento. El nuevo art. 293 castiga al que quitare la vida a otra persona según el deseo expreso y serio de la misma con pena de prisión de hasta doce años o con una pena de multa de la categoría quinta. Pero, según el apartado segundo del precepto, esta conducta no será punible «en el caso de que haya sido cometido por un médico que haya cumplido con los requisitos de cuidado recogidos en el art. 2 de la Ley sobre comprobación de la terminación de la vida a petición propia y del auxilio al suicidio, y se lo haya comunicado al forense municipal». Por su parte, el art. 294 se refiere al suicidio asistido. En el apartado primero, se castiga al que «de forma intencionada indujere a otro para que se suicide», en el caso de que el suicidio se

${ }^{27}$ El Tribunal de Apelaciones, en su Sentencia de 6 de diciembre de 2001, tuvo dudas sobre si el «sufrimiento existencial» pertenecía al ámbito tradicional de la medicina. Fue determinante del fallo la opinión de dos expertos, cuyos argumentos fueron también empleados más tarde por el Tribunal Supremo. Ver: DE VRIES, ibidem, 386.

${ }^{28}$ Estableciendo el procedimiento de notificación de la muerte que debía seguir todo médico que hubiese practicado la eutanasia (ver: TOMÁs-VALIENTE, ob. cit., 18). Esta Ley no ofrecía criterios de justificación de los supuestos de eutanasia, sino tan sólo contenía una simple regulación procedimental (aunque en los formularios que el médico que había practicado la eutanasia debía remitir al forense y al fiscal figuraban los criterios de admisibilidad de la eutanasia que se habían ido acuñando judicialmente). 
produzca, con una pena de prisión de hasta tres años o con una pena de multa de categoría cuarta. Y en el inciso segundo establece que: «El que de forma intencionada prestare auxilio a otro para que se suicide o le facilitare los medios necesarios para ese fin, será, en caso de que se produzca el suicidio, castigado con una pena de prisión de hasta tres años o con una pena de multa de la categoría cuarta. Se aplicará por analogía el artículo 293, párrafo segundo».

La Ley holandesa permite el suicidio asistido y la eutanasia cuando el médico tenga la convicción de que la petición del paciente es voluntaria y bien meditada, su sufrimiento insoportable y sin esperanzas de mejora, ha informado al paciente sobre su situación y pronóstico, ha llegado al convencimiento junto con el paciente de que no existe ninguna otra solución razonable para la situación en la que se encuentre este último, ha consultado a otro médico independiente (que ha visto al paciente y ha formulado por escrito su opinión en relación con los puntos anteriores) y ha puesto fin a la vida de su paciente o le ha ayudado a suicidarse con el máximo cuidado y esmero profesional (art. 2.1). Es apreciable la influencia del caso Chabot: la enfermedad no tiene que ser sólo física ni estar en fase terminal. Desde el punto de vista procedimental, no se requiere ningún tiempo de espera desde que se solicita la eutanasia y se practica y tampoco se exige que la petición del paciente sea escrita. En cuanto a la edad que se precisa para solicitar la eutanasia, los menores de 16 a 18 años de los que pueda juzgarse que tienen una razonable comprensión de sus intereses pueden obtener el suicidio asistido y la eutanasia incluso sin el consentimiento de los padres, aunque éstos deben estar implicados en el proceso de toma de decisión (art. 2.3). Los menores de 12 a 16 años de los que también pueda estimarse una razonable valoración de sus intereses en este asunto pueden pedir la eutanasia o el suicidio asistido, pero sólo en el caso de que sus padres o tutores estén de acuerdo (art. 2.4). Si el paciente tiene más de dieciséis años y ya no puede expresar su voluntad, pero estuvo en condiciones de realizar una valoración razonable de sus intereses al respecto antes de pasar a encontrarse en el citado estado de incapacidad y redactó una declaración por escrito que contenía una petición de terminación de su vida, el médico podrá atender esa petición (art. 2.2). Así pues, como observa Carmen Tomás-Valiente ${ }^{29}$, el sistema holandés concede a los "testamentos vitales» «un campo de juego mucho más amplio que el que les otorga el resto de los ordenamientos jurídicos», donde este tipo de documentos no pueden utilizarse válidamente para solicitar la producción activa de la muerte.

El Capítulo tercero de la Ley regula las Comisiones regionales de comprobación de la terminación de la vida a petición propia y del auxilio al suicidio. Hay

29 Ob. cit., p. 20. 
cinco en todo el país ${ }^{30}$. Estarán compuestas (art. 3.2) por un número impar de miembros, de los cuales al menos uno deberá ser jurista, y que a la vez será presidente, un médico y un experto en cuestiones éticas (junto con sus suplentes). Serán nombrados por el ministro de Justicia y el de Sanidad para un periodo de seis años (reelegibles una sola vez para ese mismo periodo: art. 4.1; podrán ser despedidos por razón de ineptitud o incapacidad o por cualquier otra razón bien fundada: art. 6). Cada Comisión tendrá un secretario, jurista, nombrado por los ministros mencionados, con voto consultivo (art. 4.2). Los miembros de la Comisión tienen obligación de secreto ${ }^{31}$, de imparcialidad ${ }^{32}$ y deberán abstenerse de opinar acerca de la intención de un médico de llevar a cabo la terminación de la vida a petición del paciente o de prestar auxilio al suicidio (art. 16).

La Comisión juzgará si el médico que ha realizado la terminación de la vida a petición del paciente o el auxilio al suicidio ha actuado conforme a los requisitos de cuidado del art. 2 de la Ley (art. 8.1). El punto de partida es el informe que exige el art. 7.2 de la Ley reguladora de los Funerales (redacción dada por la Ley de comprobación de terminación de la vida a petición propia y del auxilio al suicidio, art. 21): en casos de eutanasia o de auxilio al suicidio, el médico que ha tratado al paciente no expedirá ningún certificado de defunción y deberá informar inmediatamente, mediante la cumplimentación de un formulario, al forense municipal de las causas de dicho fallecimiento, junto con un «informe motivado» sobre el cumplimiento de los requisitos de cuidado, a los que se refiere el art. 2 de la Ley. El forense enviará este informe al Fiscal, que será quien otorgue el permiso para enterrar. Sin embargo, las estadísticas muestran que en la mitad de los casos los médicos incumplen su deber de informar a la Comisión regional correspondiente de la eutanasia que han practicado ${ }^{33}$.

La Comisión podrá solicitar al médico que complemente su informe por escrito u oralmente en el caso de que esta medida se considere necesaria para poder juzgar convenientemente la actuación del médico (art. 8.2), así como al médico forense y al médico «asesor» al que consultó el médico que atendía al

${ }^{30}$ Región de Groninga, Friesland y Drenthe; región de Overijssel, Gelderland, Utrecht y Flevoland; región de Holanda septentrional; región de Holanda del Sur y Zelanda y región de Brabante del Norte y Limburgo.

${ }^{31}$ Los miembros de la Comisión tienen una obligación de secreto de los datos de los que dispongan en la realización de sus tareas, salvo que alguna disposición legal les obligue a comunicarlo (y con el alcance concreto de esa obligación) o que su tarea haga necesaria la realización de un comunicado (art. 14).

32 Deberán abstenerse y podrán ser recusados en el caso de que se produzcan hechos o circunstancias que pudieran afectar a la imparcialidad de su dictamen (art. 15).

33 DE VRIES, ob. cit., p. 378. 
paciente (art. 8.3). La Comisión comunicará al médico por escrito su dictamen motivado (aprobado por mayoría simple de votos, aunque se requiere que todos los miembros de la Comisión tomen parte en la votación: art. 12) en el plazo de seis semanas ${ }^{34}$ a partir de la recepción del informe presentado por aquél. En el caso de que, en opinión de la Comisión, el médico no haya observado los requisitos de cuidado exigidos en el art. 2 de la Ley, la Comisión comunicará su dictamen a la Fiscalía General del Estado y al inspector regional para la asistencia sanitaria (art. 9.2.a). En ese caso, deberá informar también al médico (art. 10). La Comisión estará obligada a facilitar al fiscal toda la información que solicite y que sea necesaria para poder juzgar la actuación del médico en el caso de que no haya observado los deberes de cuidado del art. 2 de la Ley o en el curso de una investigación criminal (art. 10). La Comisión deberá llevar un registro de los casos de terminación de la vida a petición propia o de auxilio al suicidio que se le hayan notificado y hayan sido sometidos a su juicio (art. 11). Los presidentes de las Comisiones regionales de comprobación se reunirán por lo menos dos veces al año para tratar el método de trabajo y el funcionamiento de las Comisiones. A esas reuniones acudirán un representante de la Fiscalía General del Estado y un representante de la Inspección para la asistencia sanitaria (art. 13).

Una vez al año, antes del 1 de abril, las Comisiones presentarán ante el Ministro de Justicia y el de Sanidad un informe común del trabajo realizado en el año natural anterior. En este informe deberán explicitar, como mínimo, los siguientes datos: número de casos de eutanasia y suicidio asistido que se les hayan notificado y sobre los cuales han emitido un dictamen, la naturaleza de estos casos y los dictámenes y consideraciones que han efectuado de los mismos (art. 17). A partir de estos informes, los Ministros de Justicia y de Sanidad entregarán anualmente un informe al Parlamento sobre el funcionamiento de las Comisiones (art. 18).

La Ley belga relativa a la Eutanasia, de 28 de mayo de 2002 (entró en vigor el 22 de septiembre de ese año ${ }^{35}$ ), se ha dictado, como se ha dicho, siguiendo el modelo holandés. La Ley exime de responsabilidad penal al médico que practi-

34 Plazo prorrogable una sola vez por un máximo de seis semanas; la Comisión deberá comunicar esta circunstancia al médico (art. 9.3). La Comisión, de oficio o a petición del médico, podrá dar también una explicación oral al médico sobre su dictamen (art. 9.4).

35 Esta Ley se ha modificado parcialmente mediante Ley de 6 de junio de 2005 para completarla respecto del papel de los farmacéuticos y la utilización y disponibilidad de sustancias para la eutanasia. Se ha insertado un párrafo en el artículo tercero para eximir expresamente de responsabilidad penal al farmacéutico que proporciona una sustancia de este tipo sobre la base de una prescripción médica conforme a la Ley. 
que la eutanasia (definida como la intencional terminación de la vida de una persona ${ }^{36}$ por un tercero a petición de aquélla ${ }^{37}$ —art. 2-) bajo ciertas condiciones (art. 14). Una persona que muere como resultado de eutanasia se reputa como muerte natural ${ }^{38}$ (art. 15). Las diferencias principales del sistema belga y el holandés son las siguientes: en Bélgica se exige que la petición del enfermo sea escrita $^{39}$ (art. 3); los menores sólo pueden solicitarla si son emancipados, a partir de los 15 años y está consciente ${ }^{40}$; en Bélgica sólo existe una Comisión de control («Comisión Federal de Control y de Evaluación de la Aplicación de la Ley»), compuesta de 16 miembros, 8 médicos, 4 juristas y 4 profesionales implicados en la problemática de los enfermos incurables (arts. 7 a 9).

El procedimiento de control de la eutanasia cursa los siguientes trámites: todo médico que practique la eutanasia está obligado a remitir a la Comisión, dentro de los cuatro días laborables siguientes, un "documento de registro» con dos formularios: en el primero, se hará contar todos los datos de identidad del paciente y los médicos implicados (para preservar su intimidad, este docu-

${ }^{36}$ Que ha de ser un enfermo con una enfermedad incurable o con dolor insoportable físico o psicológico o con sufrimiento que no puede ser aliviado y que es provocado por una seria e incurable enfermedad o accidente (art. 3.1). Si el médico observa que el paciente no fallecerá dentro de un futuro previsible, debe observar dos obligaciones adicionales (art. 3.3): debe respetar el periodo de un mes entre la petición escrita del paciente y la ejecución de la eutanasia y debe consultar a un segundo médico, especialista en la enfermedad en presencia o psiquiatra. Esta opinión médica ajena sería la tercera opinión porque el sistema belga, al igual que el holandés, obliga a que todo paciente que solicita la eutanasia sea atendido personalmente por un segundo médico independiente (art. 3.2). La Ley belga también obliga al médico ordinario a consultar con el equipo de enfermería que le atiende normalmente (art. 3.2).

${ }^{37}$ La petición podrá formularse mediante testamento vital previo en el caso de que paciente sufra una enfermedad o accidente grave e incurable y esté irreversiblemente inconsciente. El testamento vital podrá haberse escrito antes en cualquier momento (pero sólo podrá tenerse en cuenta si se ha emitido cinco años antes del momento en el que habrá de ser aplicado), en presencia de dos testigos adultos (uno de ellos, al menos, no deberá tener ningún interés material en la muerte del enfermo) (art. 4).

${ }^{38}$ Lo cual tiene efectos, sobre todo, respecto de los acuerdos que haya suscrito, como, por ejemplo, en materia de seguros (ver: DE BONDT, «The New Belgian Legislation on Euthanasia», en International Trade \& Bussines Law Annuary, n. ${ }^{\circ} 301,2003$, p. 310).

39 Si el paciente no es capaz de escribir, lo hará una persona de su elección que no tenga ningún interés material en su muerte, en presencia del médico. El paciente puede retirar la petición en cualquier momento (art. 3.4).

40 Una proposición de Ley presentada el 15 de junio de 2006 cuestiona el límite general de edad de los 18 años y pretende que la decisión de practicar la eutanasia sea resultado del común acuerdo del menor (si tiene discernimiento), los padres o representantes legales y el equipo médico. Con independencia de que esta iniciativa prospere, es claro que la regulación belga es notablemente más restrictiva que la holandesa respecto de la posibilidad de la eutanasia de menores de 18 años. 
mento sólo podrá ser consultado si la Comisión lo decide expresamente), en el segundo se consignarán todos los detalles de la práctica eutanásica (diagnóstico de la enfermedad, naturaleza del sufrimiento, opinión de los médicos, métodos seguidos, etc.), que serán evaluados por la Comisión (art. 5); sólo en caso de duda podrá levantar el anonimato consultando el primer formulario para, si lo considera conveniente, pedir al médico datos suplementarios; si la Comisión estimara que el médico ha podido incumplir la Ley, trasladará los hechos al fiscal del lugar de la muerte del enfermo (art. 8). La Comisión está obligada a emitir un informe bianual sobre la aplicación de la Ley, en el que puede formular recomendaciones de mejora legislativa (art. 9). Un debate en las dos Cámaras parlamentarias debe llevarse a cabo sobre tal Informe en el plazo de seis meses desde su presentación (art. 13) ${ }^{41}$. Ningún médico puede ser obligado a practicar una eutanasia (art. 14). Otra diferencia significativa entre la regulación holandesa y belga es que ésta no ampara la figura del suicidio asistido, lo que fue puesto de relieve y criticado en su momento por el Avis del Conseil d'État sobre la proposición de la Ley, de 20 de junio de 2001. El Consejo de Estado no comparte la opinión de que la licitud de la eutanasia comprende, de suyo y sin más especificaciones, la de los suicidios asistidos, ya que se trata de dos conductas distintas (aunque semejantes); más aún, considera que esta omisión de la Ley discrimina a las personas que deseen ser ayudados en su suicidio frente a las que prefieran que un tercero acabe con su vida a su petición. En la práctica, sin embargo, la Comisión ha venido considerando que el suicidio asistido también estaría cubierto por la Ley.

A esta fecha, se han evacuado ya dos Informes a las Cámaras legislativas por parte de la Comisión Federal, uno relativo al periodo de 22 de septiembre de 2002 hasta el 31 de diciembre de 2003, y otro desde el 1 de enero de 2004 al 31 de diciembre de 2005. Es posible, pues, formular una evaluación sobre el periodo inicial de aplicación de la Ley. De septiembre de 2002 a enero de 2004 hubo en Bélgica 259 casos de eutanasia (20 por mes de media ${ }^{42}$ ); sólo en uno se aplicó lo dispuesto en un testamento vital; la mitad fueron mujeres y la mitad hombres; la edad media en el $48 \%$ de los casos fue de 60 a 79 años (el $32 \%$ de 40 a 59); el $54 \%$ fallecieron en hospital y el $41 \%$ en domicilio; el diagnóstico fue de cáncer en el 82,5\% de los casos (una enfermedad neuro-degenerativa en el 9,5\%); los sufrimientos físicos mencionados fueron: dolores $(51 \%)$, disnea (37,5\%), obstrucción digestiva $(31,5 \%)$ y los psicológicos: pérdida de dignidad y esperanza $(40 \%)$ y dependencia (27\%); la manera de practicarla en el $91,5 \%$ de los casos fue in-

\footnotetext{
41 Ver: De Bondt, ibidem, pp. 301 y ss., Tomás-Valiente, ibidem, 22.

42259 sobre 105.000 fallecidos en ese mismo periodo supone el 0,2\% de muertes.
} 
yectando pentotal o similares (un inductor de la inconsciencia) y, si la muerte no llegaba a los pocos minutos, se inyectaba un paralizante neuro-muscular que provocara una parada respiratoria. Los datos estadísticos del segundo informe son bastante semejantes. Entre 2004 y 2005 fallecieron por eutanasia 742 personas (sumadas a las 259 anteriores arroja la cifra de 1.001 fallecidos en los tres años y tres meses considerados). Sólo trece personas murieron por aplicación de su testamento vital; el resto estaba consciente. El 52\% fueron hombres y el $48 \%$ mujeres. El 43\% en 2004 y el 54\% en 2005 tenían entre 60 y 79 años (33\% y $24 \%$ respectivamente entre 40 y 59 años). El 54\% fallecieron en hospital y el 39\% en su domicilio. El 83\% a causa de cáncer. El 89\% de personas recibió la inyección de pentotal. La Comisión aceptó el informe del médico en el 73\% de los casos; solicitó información adicional (para lo cual tuvo que abrir el informe de datos confidencial) en el 17\%; y, lo que resulta muy llamativo, en ninguna oportunidad hasta ahora ha tenido que dar traslado de los informes al ministerio fiscal (es decir, los médicos han cumplido las exigencias legales en todos los casos).

Estos datos permiten a la Comisión formular algunas valoraciones ${ }^{43}$. Califica, por ejemplo, de «moderado» el incremento del segundo periodo respecto del primero ( $\mathrm{y}$ achaca al incremento a que la práctica de la eutanasia se ha ido conociendo más entre los belgas; la media total es de 31 eutanasias al mes, el 3,6 por mil de todos los fallecimientos; la Comisión considera que el número de eutanasias se ha "estabilizado»). Observa también la curiosa desproporción que existe entre los solicitantes de habla francesa (en torno al 15\% de los casos) y los de habla flamenca (85\%), aunque no aporta ninguna hipótesis explicativa del hecho. Otro dato curioso es que, en contra de lo que, quizás, podría pensarse, el grupo de edad prevalente de entre los solicitantes de la eutanasia no es el de los más mayores: con más de 70 años, a pesar de ser, lógicamente, el grupo de personas con mayor número de fallecimientos, «sólo» pidieron la eutanasia menos del $15 \%$, lo cual sugiere que la mayor edad no parece ser el factor determinante para solicitarla. También es muy reducido (sobre todo si lo comparamos con la práctica holandesa) el número de eutanasias de enfermos inconscientes que han manifestado antes su voluntad en este sentido (14 casos de 1.001).

De los Informes se desprende también algunas cuestiones más problemáticas. Una de ellas se refiere al hecho de que, aunque escasas, en algunas ocasiones (concretamente en ocho) la eutanasia se ha llevado a cabo mediante barbitúricos

${ }^{43}$ La Comisión también lleva a cabo algunas recomendaciones, como, por ejemplo, la necesidad de informar más a la población y a los médicos sobre la eutanasia y sus procedimientos; formar específicamente a los médicos en "la gestión del final de la vida» y la práctica correcta de la eutanasia, etc. 
ingeridos oralmente por el propio sujeto, lo que hace pensar que no se trataría, en realidad, de casos de eutanasia sino de suicidio asistido por el médico. Esto ha provocado un debate en el seno de la Comisión porque, como se ha indicado, hay dudas sobre si el suicidio asistido está amparado por la Ley. Algunos miembros de la Comisión (la minoría) son partidarios de que la Ley expresamente se refiera también al suicidio asistido, pero la mayoría ha considerado que esto confundiría más que aclararía el marco normativo, estimando que la Ley vigente presta cobertura ya al suicidio asistido. En el segundo Informe, para el periodo 2004-2005, algunos miembros de la Comisión han juzgado que, en ciertos casos, se habría sobrevalorado el sufrimiento "psicológico» del enfermo (al «estilo holandés» podríamos decir), pero la mayoría no lo ha considerado así.

Así pues, el modelo belga, al menos de momento, es un sistema de eutanasia «abierto» o "general», al modo holandés, pero, a diferencia de éste, de formato reducido. Está estructuralmente limitado porque se ciñe a mayores de edad, fundamentalmente a enfermos en fase terminal, conscientes en el momento de formular y recibir la eutanasia, y en el marco de un sistema con mayor número de garantías procedimentales que el holandés. La persona/tipo a la que se practica la eutanasia en Bélgica habla flamenco, es mayor pero no demasiado, tiene cáncer en fase terminal, se encuentra consciente y fallece en un hospital.

Mientras que el sistema belga no suele ser objeto (aún) de críticas (aunque pesa sobre él la sospecha de "seguidismo» de sus vecinos del norte), el holandés es diana de todo tipo de impugnaciones, dentro y fuera del país. Algunas se refieren al procedimiento. La Liga de Médicos holandesa, por ejemplo, cuestiona la amplia discrecionalidad que tiene el médico para decidir cuándo su paciente tiene un «sufrimiento intolerable e irreversible»; critica que antes de recurrirse a la eutanasia no se requiera que el paciente utilice un procedimiento de medicina paliativa; considera insuficiente que no se exija una determinada cualificación para el segundo médico (por lo que su opinión «es una falsa garantía... una determinación subjetiva, aunque se repita dos veces, no se convierte por ello en objetiva»); observa que las Comisiones regionales pueden seguir criterios distintos; llama la atención sobre el hecho de que no es posible «una adecuada supervisión» de las decisiones médicas de aplicar la eutanasia; critica la eutanasia de los menores; solicitan que se reconozca expresamente la objeción de conciencia del personal médico, etc. Pero, por encima de todas las impugnaciones, sobresalen dos, la débil garantía que supone un control a posteriori ${ }^{44}$, y el ar-

44 En el mismo sentido, entre otros muchos, JOCHEMSEN, «Legalization of eutanasia in the Netherlands», en Issues in Law and Medicine, vol. 16, 2001, p. 286. Si los médicos ni siquiera llegan a informar, lo cual ocurre no pocas veces, el control será imposible. 
gumento de la pendiente resbaladiza. En efecto, es observable cómo el ámbito, en principio y por norma, excepcional de la eutanasia se ha ido ampliando progresivamente en Holanda desde el suicidio asistido a la eutanasia, de los enfermos en fase terminal a los enfermos crónicos, de la eutanasia voluntaria a la no voluntaria ${ }^{45}$ y de la enfermedad física al sufrimiento psicológico (y casi al existencial). Las cifras de eutanasia pueden estimarse, de hecho, muy altas. La práctica de la eutanasia en Holanda está recogida, fundamentalmente, en tres informes elaborados por el Gobierno en 1990, 1995 y 2001. Holanda es un país de algo más de 16 millones de habitantes. Pues bien, de los 128.824 fallecidos en 1990, 2.300 lo fueron mediante eutanasia activa voluntaria, 400 por suicidio médicamente asistido y 1.000 por eutanasia activa no actualmente voluntaria ${ }^{46}$. En 1995, fallecieron 135.675 holandeses y, de ellos, 3.200 mediante eutanasia activa voluntaria, 400 por suicidio médicamente asistido, 900 por eutanasia activa no voluntaria y 95 por eutanasia neonatal. En 2001, de los 140.377 fallecidos, 3.700 lo fueron por eutanasia activa voluntaria, 300 por suicidio médicamente asistido, 1.000 por eutanasia activa no voluntaria y 100 por eutanasia neonatal.

Estas estadísticas son incompletas porque son anteriores a la fecha de entrada en vigor de la Ley, no todos los médicos informan de que han realizado la eutanasia, como se ha indicado, no recogen datos sobre suicidios médicamente asistidos de pacientes psiquiátricos, ni los datos son completos sobre sedaciones terminales dirigidos principalmente a terminar con la vida del paciente, etc. ${ }^{47}$. Las cifras sólo valen, pues, de modo aproximativo al fenómeno. Pero un hecho parece claro: son cifras altas, crecientes y expansivas; muestran que en Holanda la eutanasia tiende a ser vista como una práctica médica aceptada. No son las 30 personas que fallecen de media al año en Oregón por suicidio asistido por mé-

${ }^{45}$ Los tribunales han acabado admitiendo la eutanasia de niños con enfermedades graves. En 1993, se trató de una niña de tres días que tenía lesiones cerebrales y en la médula espinal; los médicos decidieron no operar y uno de ellos acabó con su vida mediante una dosis letal de anestésicos. El Tribunal de Apelaciones de Ámsterdam (sentencia de 7 de noviembre de 1995) les eximió de responsabilidad penal, a la vez que promovía el desarrollo de la jurisprudencia sobre los casos de eutanasia de recién nacidos con defectos congénitos. El Tribunal de Apelaciones de Leeuwarden (sentencia de 4 de abril de 1996) encontró justificable la conducta de un médico que había provocado la muerte de un niño de 26 días enfermo de trisomía.

46 Se trata de enfermos en estado de inconsciencia que, o bien tienen un testamento vital en ese sentido, o bien el médico que los trata y/o su familia opinan que su sufrimiento es insoportable e irreversible.

47 También hay que tener en cuenta que en un sistema que permite la eutanasia activa directa, las distinciones con las formas pasiva e indirecta se relajan al máximo, de modo que tal vez no pocas eutanasias en realidad directas puedan quizás presentarse como pasivas o indirectas. 
dico $^{48}$. Aplicado a España el porcentaje de 2,6 de eutanasias por fallecidos (dato holandés de 2001, en la actualidad cabe suponer que sería mayor), por ejemplo a la cifra de 387.019 difuntos en España en 2005, resultaría un número no inferior a 10.000 muertos por año mediante eutanasia activa directa.

Algunas ideas de las experiencias holandesa y belga también podrían tenerse en cuenta respecto de una eventual despenalización de la eutanasia o del suicidio asistido en España.

1. $\left.{ }^{a}\right)$ Un hecho explicativo de la radical (al menos en la práctica) solución holandesa a favor de eutanasia y suicidio asistido es la toma de postura en este sentido de un sector importante de la profesión médica, ya desde el influyente trabajo de J.H. van de Berg en $1969^{49}$. Por otro lado, cabe recordar que, con una interpretación generosa de "la fuerza mayor», los tribunales toleraron ampliamente, incluso mucho antes de que el marco legal vigente otorgara cierta claridad al asunto, ciertos modos de llevar a cabo la eutanasia y el suicidio asistido como prácticas médicas corrientes. Esta actividad judicial ha sido determinante en la evolución de la solución jurídica que se ha prestado en Holanda al asunto. La Ley no ha sido el primer paso de aceptación de la eutanasia, sino el último, tras la inequívoca evolución jurisprudencial (los criterios de cuidado del art. 2 de la Ley han surgido de una progresiva decantación judicial). De igual modo, otro hecho muy relevante es que un porcentaje altísimo de la población holandesa acepta la despenalización de la eutanasia y, cabe suponer, también el modo en que se entiende esto allí en la práctica ${ }^{50}$. Un consenso médico, judicial y social tan mayoritario a favor de la eutanasia no tiene, hasta donde sé, parangón en ningún otro país del mundo y remite a una concepción ideológica ante el fenómeno de la muerte peculiar y escasamente exportable.

48 Oregón tiene una población superior a los tres millones y medio de habitantes, entre cuatro y cinco veces menos que Holanda; pero aunque multiplicáramos por cuatro o por cinco la cifra de personas que deciden recurrir al suicidio asistido en Oregón estaríamos aún muy por debajo de las que en Holanda lo hacen.

49 «Poder Médico y Ética Médica». En 1980, otro trabajo de un médico, «La justificación de la Eutanasia. Manual para la profesión médica», de PIETER ADMIRAL, tuvo cierto éxito en la opinión pública. De ello se hace eco Mora Molina, ibidem, p. 536.

${ }^{50}$ DE VRIES (ob. cit., p. 365) recuerda cómo en 2001, poco antes de que se aprobara la Ley, el Ministro de Sanidad afirmó en la Cámara Alta que el 80\% de los holandeses apoyaban la posibilidad de la eutanasia como una opción para los pacientes con grave sufrimiento y sin esperanzas de mejora. Mora Molina invoca una cifra cercana al 90\%, (p. 538). Esto no era así en 1966, donde el $48,6 \%$ de la población se mostraba en contra. MorA achaca a la labor de la Asociación Holandesa para la Aceptación de la Eutanasia Voluntaria un papel determinante en el progresivo, pero profundo, cambio de criterio de la opinión pública. 
$\left(2{ }^{a}\right)$ Otra peculiaridad altamente significativa del modelo holandés, que abunda en la tesis de su inexportabilidad a otros ordenamientos, es el hecho de que allí la cuestión no se ha planteado desde la idea de la autonomía del paciente y sus derechos fundamentales ${ }^{51}$, entre otras cosas porque en Holanda no existe jurisdicción constitucional y, por tanto, no hay quien asegure los derechos fundamentales frente al legislador. La licitud de la eutanasia bajo ciertas condiciones es un derecho de naturaleza estrictamente legal (una reforma penal) y la cuestión se ha planteado no en la arena de los derechos fundamentales en presencia, sino desde el proceso político ordinario, con una aproximación pragmática gravitante sobre la lex artis médica (de ahí, nuevamente, la importancia del consenso médico crecientemente favorable a la extensión de la eutanasia). El problema se ha planteado en Holanda no desde la perspectiva de la persona que pedía la muerte, sino, fundamentalmente, desde el acto médico que se la proporcionaba. Fueron primero los tribunales los que abrieron brecha en la tipificación penal de la eutanasia con su interpretación amplia del concepto de «fuerza mayor» (que incluye el «estado de necesidad» del médico en ciertos casos) y más tarde el legislador quien codificó los criterios acuñados antes judicialmente.

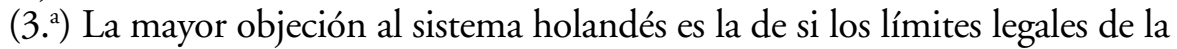
eutanasia han sido desbordados en la práctica. Ciertamente, la eutanasia sigue siendo, en general, un delito y se permite "sólo» sobre la base de consideraciones de carácter médico (que pueden llegar a valorar la eutanasia como una alternativa razonable a un sufrimiento "médico» insoportable e irreversible). Pero los datos estadísticos permiten suponer que la idea de que se han roto los diques de contención de una suficiente protección jurídica de la vida no es descabellada. No podemos olvidar, además, que el sistema no ofrece suficiente control, (un control que, además, se realiza, y no siempre, a posteriori) por lo que el riesgo de desbordamiento es todavía mayor.

\section{SUICIDIO ASISTIDO POR MÉDICO: EL CASO DE OREGÓN}

El modelo legal de suicidio asistido por médico implantado en el Estado de Oregón es verdaderamente sorprendente en el contexto de los Estados Unidos porque, habiendo sido muchos los Estados donde se han intentado diversas ini-

51 Insiste en esta idea DE VRIES (ibidem, p. 366). Tampoco Holanda ha abrazado la doctrina de los derechos no enumerados o implícitos, de modo que carece de esta vía de expansión de los derechos (p. 366). 
ciativas sobre ayuda a morir (California, Washington, Florida, etc. ${ }^{52}$ ), es, sin embargo, el único lugar donde ha triunfado ${ }^{53}$, no sin importantes dificultades, como veremos. Se trata, pues, de un interesante término de comparación.

La Dead Whit Dignity Act no fue aprobada por el legislador estatal, sino a iniciativa popular (permitida como forma de aprobación de las leyes por el art. IV, sección I, de la Constitución de Oregón), mediante referéndum (con el voto favorable del 51\%) el 8 de noviembre de $1994^{54}$. Sin duda, es significativo el alto grado de aceptación ciudadana que el sistema de suicidio asistido por médico tiene en Oregón desde el principio, lo que, unido a la original posibilidad procedimental de que el cuerpo electoral puede aprobar directamente leyes, subraya el carácter excepcional del modelo de Oregón y dificulta su exportación a otros países, aunque está sirviendo como fuente de inspiración en Estados Unidos. Se ha señalado ${ }^{55}$ como uno de los factores críticos del éxito de la iniciativa en Oregón el hecho de que la medicina letal se auto-administre por el paciente por vía oral, excluyendo el uso de inyecciones letales (que sí se preveía inicialmente, pero se suprimió después). Pero hay otros ${ }^{56}$ : Oregón es un Estado donde

52 La mayoría de Estados, cerca de 40, han mantenido o aprobado recientemente leyes que expresamente prohíben el suicidio asistido. Al menos 16 de esos Estados han considerado y, en su caso, rechazado iniciativas populares que perseguían legalizar el suicidio asistido (GORSUCH, ibidem, p. 1348).

53 Bien es cierto que, como ha sido observado («The legalization of physician-assisted suicide: creating a regulatory Potemkin village», en University of Richmond Law Review, vol. 30, 1996, p. 2), esto ha sido así, en gran medida, porque el debate en Oregón ha girado sobre el suicidio asistido por médico mientras que en el resto de lugares ha sido la eutanasia la cuestión planteada. Este hecho viene a demostrar la significativa diferencia entre suicidio asistido y eutanasia también desde el punto de vista de la percepción ciudadana.

${ }^{54}$ El precepto citado establece que «el pueblo se reserva el poder de proponer leyes y enmiendas constitucionales y de aprobarlas o rechazarlas, independientemente de la Asamblea legislativa, y también se reserva el poder de aprobar o rechazar cualquier acto de la Asamblea legislativa». Esta forma tan incisiva de democracia directa es conocida como "sistema Oregón» (D. Schuman, "The Creation of the Oregon Constitution", Oregon Law Review, vol. 74, 1995, p. 611). Oregón sólo ha tenido una Constitución, elaborada en un solo mes, en 1857. Según SCHUMAN, los sesenta constituyentes, la mayoría granjeros, «copiaron» la mayor parte de los artículos del resto de Constituciones norteamericanas, pero fueron originales en la creación de técnicas de democracia directa, como es la initiative: una forma de iniciativa legislativa propuesta por un cierto número de ciudadanos que se somete al voto del electorado y, si éste la aprueba, se convierte directamente en ley, sin intervención del cuerpo legislativo.

55 C. A. PratT, «Efforts to Legalize Physician-Assisted Suicide in New York, Washington and Oregon: A Contrast Between Judicial and Initiative Approaches -Who Should Decide?», en Oregon Law Review, vol. 77, n. ${ }^{\circ}$ 4, winter 1998, p. 1082.

56 C. A. PratT, ibidem, p. 1100. 
se reconoce gran valor al principio de autonomía personal; es uno de los Estados más secularizados de la Unión, donde las confesiones religiosas juegan un papel social y político menor. Además, en Oregón se da la cifra más baja en Norteamérica de muertes en hospital (algo más del 20\% frente al 35\% de la media federal); sus habitantes prefieren morir en casa. Y, por último, es observable la influencia de una importante asociación nacional pro-ayuda a morir, la Hemlock Society, que tenía sus cuarteles generales en Eugene (Oregón), por no hablar de la publicitada actividad del doctor Jack Kevorkian, que también se hizo sentir en Oregón ${ }^{57}$.

El punto de arranque, sin embargo, ante la opinión pública de Oregón, de la cuestión de legalizar el suicidio asistido, provino del caso Elvin Sinnard. Este señor puso fin a la vida de su esposa, que sufría una enfermedad cardiaca crónica, en 1989, siguiendo las recomendaciones de la Hemlock Society. En 1990, Sinnard y un grupo de abogados y médicos (organizados bajo el nombre Oregon Right to Die) propusieron lo que más tarde sería la Ley de Muerte con Dignidad.

El 23 de mayo de 1994, quince días después de que la Ley entrara en vigor, una coalición de abogados, médicos y enfermos planteó una class action contra ella ante un Tribunal de Distrito Federal en Eugene (Oregón) alegando su inconstitucionalidad. Se trata del caso Lee v. Oregon. El argumento principal de los demandantes era que la Ley violaba la cláusula de igual protección porque, de modo no razonable, denegaba sólo a los enfermos terminales la protección contra el suicidio asistido que prohibía con carácter general. La defensa del Estado se opuso a esta tesis. Primero, porque la Ley era opcional y no obligaba a todos los enfermos terminales a acudir al procedimiento previsto en ella. Segundo, el Estado aportó cinco razones para tratar de modo desigual a los enfermos terminales: $\left(1 .^{a}\right)$ Evitar daños y sufrimientos innecesarios. (2..$\left.^{a}\right)$ Preservar el derecho de las personas adultas de adoptar decisiones sobre su propia salud. (3. $\left.{ }^{a}\right)$ Evitar trágicos casos de suicidio, proporcionando un procedimiento de muerte más humana y digna. $\left(4 .^{a}\right)$ Evitar a los enfermos terminales y a sus familias excesivos costes económicos. (5. ${ }^{\text {a }}$ Proteger a los enfermos y a sus familias de intromisiones no queridas sobre sus asuntos personales.

Los argumentos ofrecidos por el Estado no convencieron al Juez Michael Hogan, quien concluyó, con los demandantes, que la Ley violaba la cláusula constitucional de igual protección de la decimocuarta Enmienda. La clasificación «enfermos terminales» sería discriminatoria por «sobre-inclusiva» dado que no

57 Durante los noventas, el Dr. KEVORKIAN quitó directamente la vida o ayudó a morir a más de 130 personas. Su actividad atrajo la atención de los medios y puso en la agenda pública el problema de la despenalización de la eutanasia y del suicidio asistido (GORSUCH, ob. cit., p. 1348). 
estaba suficientemente limitada. Y, además, la Ley discriminaba a los enfermos terminales porque les otorgaba menos protección constitucional contra el suicidio que la prevista para enfermos no terminales. La Ley no incurría en discriminación cuando se aplicaba a los enfermos terminales competentes (son, en principio, razonables las políticas públicas que permiten elegir el enfermo basándose en el principio de autonomía), pero no ofrecía suficientes garantías para asegurar que el suicidio asistido por médico estuviera disponible sólo para enfermos terminales adultos y competentes que voluntariamente pidieran la medicación letal. Las deficiencias serían de dos tipos. Primera, el procedimiento para diferenciar enfermos terminales competentes e incompetentes era inadecuado porque no era obligatorio el examen del psiquiatra (sólo interviene a petición del médico que atiende ordinariamente al paciente cuando estime que sufre cualquier desorden psicológico o depresión) y porque los dos médicos que tienen que intervenir no son necesariamente especialistas en psicología o psiquiatría y, por tanto, podrían no tener la habilidad profesional para detectar signos clínicos de depresión. Segunda, la Ley sólo exigía que el enfermo fuera competente en el momento de solicitar la medicación, pero no en el momento de tomarla, $y$, por tanto, no aseguraba la voluntariedad del paciente en ese momento crítico.

En febrero de 1997, la Ninth Circuit Court of Appeals se opuso a la Sentencia Lee v. Oregon y ordenó el archivo del caso por razones procesales (falta de legitimación de los demandantes, etc.). Los demandantes intentaron llevar el caso ante el Tribunal Supremo Federal, pero éste no lo admitió.

También en 1997, pero en noviembre, el Congreso sometió a referéndum la Ley (Measure 51) y, de nuevo, los ciudadanos de Oregón convalidaron su apoyo del procedimiento de suicidio asistido por médico, con el $60 \%$ de los votos a favor $^{58}$. Es decir, esta Ley ha pasado dos veces por el cuerpo electoral, en 1994, cuando se aprobó directamente por él y tres años después rechazando derogarla, y con mayor apoyo popular que la primera, por cierto (del 51 al 60\%). Las controversias, sin embargo, no finalizaron. En 2001 el Attorney General John Ashcroft propuso una Interpretative Rule de la Ley federal de Substancias Controladas (1970), según la cual ésta prohibiría a los médicos prescribir tales substancias para usar en suicidios asistidos por médicos, ya que ello no sería una práctica médica «legítima». La Ley de Substancias Controladas relaciona en una serie de listados (del II al V) drogas que están aprobadas para uso médico, pero sujeto a diversas restricciones: el médico debe estar registrado en la Agencia

${ }^{58}$ La consulta, celebrada el 4 de noviembre de 1997, se llamó Repeals Law allowing terminally ill adults to obtain letal prescription. 
federal correspondiente (la Drug Enforcement Administration, D.E.A.) y su prescripción debe perseguir «un objetivo médico legítimo». En este punto se concentraba la cuestión litigiosa. Hasta la fecha, todos los medicamentos recetados bajo la Ley de Muerte con Dignidad han sido barbitúricos, que son substancias controladas (del listado II); a juicio de Ashcroft, su uso en los suicidios asistidos por médico no perseguía un «objetivo médico legítimo" ${ }^{59}$. En respuesta a una demanda interpuesta contra esta interpretación por el Estado de Oregón, un Tribunal Federal de Distrito sostuvo el 17 de abril de 2002 la validez de la Ley de Muerte con Dignidad y la incorrección de la tesis de Ashcroft. El Ninth U.S. Circuit Court of Appeals denegó el 26 de mayo de 2004 el recurso que contra la decisión del Tribunal de Distrito había formulado el Attorney General. Según este órgano judicial, la interpretación del Attorney General de los Estados Unidos convertía un procedimiento médico autorizado por un Estado en un delito federal, alterando el balance de poderes entre los Estados y el Gobierno federal. Y, además, era contraria a la propia Ley de Substancias Controladas, que tiene por objeto tan sólo el control del consumo y tráfico de drogas convencionales. La Ley reprime, por supuesto, que los médicos utilicen su poder de prescribir para participar en el tráfico de drogas, pero no persigue, de ningún modo, regular la práctica de la medicina. El Tribunal también advierte que la Ley de Substancias Controladas otorga ciertas competencias al Attorney General, como, por ejemplo, la de añadir o quitar substancias controladas según los avances científicos y médicos, pero siempre a partir de la opinión de la Secretaría de Salud, y, en todo caso, la Ley de ninguna manera le autoriza a tomar decisiones de política sanitaria.

Por último, el asunto llegó al Tribunal Supremo federal, que falló el 17 de junio de 2006 confirmando la decisión de los tribunales inferiores. El Supremo falló, en la Sentencia Gonzales v. Oregon, que la Ley de Substancias Controladas no permite al Attorney General prohibir a los médicos prescribir drogas reguladas para utilizarlas en un suicidio asistido por ellos bajo una ley estatal que permita tal procedimiento. El Attorney General carece de autoridad para declarar el suicidio asistido antijurídico bajo la Ley de Substancias Controladas porque ésta se refiere únicamente al consumo y tráfico de drogas ilícitas. La Sentencia es inte-

59 Esta ofensiva judicial vino acompañada de presiones contra el personal sanitario. De hecho, según la Guía de aplicación de la Ley de Muerte con Dignidad para los Profesionales Sanitarios $(2005,4)$, algunos médicos de Oregón «prescriben de modo no oficial medicación contra el dolor para pacientes terminales por miedo a ser objeto de investigación por la Drug Enforcement Administration (D.E.A.). Este Informe anima, sin embargo, a los médicos a evitar, por temor a la D.E.A., cualquier reducción de la medicación en el tratamiento del dolor de los enfermos terminales, a la vez que les recuerda que deben documentar cuidadosamente su actividad en estos casos. 
resante por varios motivos. Como sagazmente observa el conservador Justice Scalia en su voto discrepante, el mensaje principal de esta Sentencia (en línea con sus otras decisiones en este campo) es que la decisión sobre permitir o no el suicidio asistido no corresponde a las instituciones federales, sino a las estatales. El Tribunal prefiere aquí la tesis de la experimentación legislativa estatal, los Estados como laboratorio de políticas sociales. A pesar del intento del Attorney General (que pertenece a la conservadora administración Bush, opuesta al suicidio asistido), el Tribunal Supremo rehúsa la oportunidad de convertir en impracticable el procedimiento estatal de suicidio asistido por el expediente indirecto de reconocer la competencia federal sobre la determinación de qué usos médicos de las drogas son legítimos y cuáles no. Pero hay otro aspecto de la Sentencia que resulta curioso e incluso paradójico. Resulta que los firmantes conservadores del voto discrepante común (que firmó Scalia y al que se adhirieron el Chief Justice Roberts y Thomas -éste también presentó un voto discrepante propio) son conocidos defensores de los poderes de los Estados frente al de la Federación ${ }^{60}$ y, sin embargo, en este asunto se encontraban, en principio, «descolocados», ya que se veían obligados, por su ideología conservadora, a defender el poder de la Federación sobre el de un Estado. Es decir, el caso presentaba un conflicto que podríamos denominar de contradicción interna del pensamiento jurídico-político conservador tal como se entiende en los Estados Unidos. ¿Cómo se enfrentan a ello los magistrados discrepantes? Su argumentación intenta convencer de que, según la jurisprudencia del Tribunal Supremo, el Attorney General sí tiene ese poder de interpretar la Ley de Substancias Controladas. En un momento determinado, abordan, sin embargo, la contradicción aludida. Es "fácil simpatizar», escribe Scalia, con la posición de la mayoría del Tribunal de que la materia del suicidio asistido no es asunto del Gobierno federal. Ciertamente, el permiso o prohibición del suicidio asistido no está entre los poderes enumerados o conferidos a los Estados Unidos por la Constitución y cae dentro del ámbito de moralidad pública (bonos mores) tradicionalmente remitida al denominado "poder de policía» de los Estados. Pero entonces, repone el propio Scalia, tampoco la prohibición del consumo y tráfico de drogas está entre los poderes federales enumerados. $\mathrm{Y}$ así como esta materia, según una firme jurisprudencia, puede entenderse amparada bajo la cláusula federal de comercio, también la del suicidio asistido «incuestionablemente» se podría incluir en ella (basta comparar esta idea con las opiniones que Scalia y, sobre todo, Thomas, escriben en United States $v$. Lopez, de 1997, sobre los límites del poder federal de comercio como cláusula

${ }^{60}$ Ver: F. REY, «EEUU v. López y el nuevo federalismo norteamericano», Revista Española de Derecho Constitucional, n. ${ }^{\circ}$ 51, septiembre-diciembre de 1997, pp. 273 y ss. 
habilitadora de competencias para apreciar el notable cambio de postura en que incurren) Por último, Scalia se sincera aún más: «Yo pienso que no hay duda de que si el término "propósito médico legítimo» (de la Ley de Substancias Controladas) tiene algún significado, es seguramente el de excluir la prescripción de drogas para producir la muerte». Por fortuna en este caso, la mayoría del Tribunal ha preferido tener en cuenta lo que realmente persigue y dice la Ley en vez de intentar encontrar en ella las propias elecciones ideológicas o morales.

Con todo, en medio de esta larga batalla política y jurídica contra ella, la Ley de Muerte con Dignidad ha sido aplicada ininterrumpidamente desde 1998 (tras superar el segundo referéndum ${ }^{61}$ ). Su contenido es el siguiente. La Ley permite solicitar por escrito ${ }^{62}$ medicación con el propósito de poner fin a su vida a cualquier adulto (individuo mayor de 18 años), competente (esto es, a juicio del tribunal o de los médicos que le atienden, un paciente con capacidad de adoptar y comunicar decisiones sobre su salud a sus cuidadores), residente en Oregón, al que se hubiera diagnosticado una enfermedad terminal (enfermedad incurable e irreversible que, de acuerdo a un razonable juicio médico, confirmado por una segunda opinión, produzca la muerte en el plazo máximo de seis meses) por el médico que le atiende de modo ordinario (attending physician) y por otro especialista (consulting physician), y que hubiese expresado voluntariamente su deseo de morir (127.805\$2.01). La solicitud debe firmarse por el paciente y dos testigos que, en presencia de aquél, atestigüen que es competente, actúa voluntariamente y no está siendo coaccionado. Uno de los testigos deberá ser una persona que

${ }^{61}$ Fue modificada parcialmente por el Congreso de Oregón el 30 de junio de 1999.

${ }^{62} \mathrm{El}$ artículo 127.897\$6.01 establece el formulario de esta solicitud: «PETICIÓN DE MEDICACIÓN PARA ACABAR CON MI VIDA DE UNA MANERA HUMANA Y DIGNA. Yo, ..., adulto en plena posesión de mis facultades mentales. Estoy sufriendo de ..., que mi médico ordinario ha diagnosticado como enfermedad terminal, lo que ha sido confirmado por un médico especialista. He sido completamente informado de mi diagnóstico, pronóstico, naturaleza de la medicación a ser prescrita y los potenciales riesgos asociados, el resultado esperado y las alternativas, incluyendo cuidados, control del dolor y atención terminal. Solicito que mi médico ordinario me prescriba medicación que ponga fin a mi vida de una manera humana y digna.

He informado a mi familia de mi decisión y tomado sus opiniones en consideración (ó «He decidido no informar a mi familia de mi decisión» ó «No tengo familia a quien informar de mi decisión»). Comprendo que tengo el derecho de rescindir esta solicitud en cualquier momento. Comprendo la fundamental importancia de esta solicitud y espero morir al tomar la medicación que se me prescriba. También comprendo que aunque la mayoría de las muertes suceden dentro de las tres primeras horas, mi muerte podría tener lugar después y mi médico me ha advertido de esta posibilidad. Formulo esta solicitud voluntariamente y sin reservas, y acepto la completa responsabilidad moral por mis acciones.

Firma y fecha». 
no sea pariente del paciente por sangre, matrimonio o adopción, ni su heredero, ni propietario, empleador o empleado de cualquier centro donde reciba atención médica el paciente en el tiempo de presentación de la solicitud. El médico ordinario que trata al paciente tampoco podrá ser testigo $(127.810 \$ 2.02)^{63}$.

El médico ordinario que reciba la solicitud tiene las siguientes responsabilidades (127.815\$3.01): Establecer el diagnóstico inicial de la enfermedad terminal del paciente, así como que es capaz y realiza la petición de forma voluntaria; solicitar que el paciente demuestre su residencia en Oregón ${ }^{64}$; asegurarse de que el paciente adopta una decisión informada ${ }^{65}$, cuyo contenido es: diagnóstico, pronóstico, riesgos potenciales asociados con la medicación que se le prescriba, resultado probable de la medicación prescrita, alternativas factibles, incluyendo control del dolor, cuidados terminales, etc.; remitir al paciente a un médico especialista para la confirmación médica del diagnóstico y de que es competente y actúa voluntariamente; remitir al paciente, cuando pueda sufrir depresión o cualquier tipo de desorden psicológico o psiquiátrico que le impida decidir con plenitud de criterio, a otro médico especialista ${ }^{66}$; recomendar al paciente que se lo comunique al pariente más cercano ${ }^{67}$; aconsejar al paciente sobre la importancia

${ }^{63}$ En el formulario de la solicitud se especifica también la forma que habrá de revestir la «Declaración de testigos»: «Nosotros declaramos que la persona que firma esta solicitud: (a) Es conocida personalmente por nosotros o nos ha otorgado pruebas de su identidad. (b) Firma esta solicitud en nuestra presencia. (c) Parece estar en plena posesión de sus facultades mentales y no bajo fraude o influencia debida. (d) No es paciente de cualquiera de nosotros. Firmas y fecha» (127.897\$6.01).

${ }^{64}$ Por ejemplo, con la posesión de un permiso de conducción de Oregón, o por estar en el censo electoral, o probando que tiene propiedades o que tributa allí (127.860\$3.10).

${ }^{65} \mathrm{La}$ Guía para la aplicación de la Ley de Muerte con Dignidad para profesionales sanitarios (p. 8) concede a la adecuada prestación de información por parte del médico el valor de «una potente intervención terapéutica» en la medida en que «la mayoría de los pacientes que inicialmente consideran el suicidio asistido no persisten, sin embargo, en la idea cuando sienten que sus necesidad son efectivamente cubiertas». De hecho, aunque se suicida de acuerdo con la Ley menos de un residente en Oregón de cada mil, ciento setenta valoran el suicidio asistido como una opción.

${ }^{66} \mathrm{El}$ artículo $127.825 \$ 3.03$ especifica que «No será prescrita medicación para poner fin a la vida de una manera digna y humana hasta que este médico (especialista) determine que el paciente no sufre ningún desorden psicológico o psiquiátrico o depresión».

${ }^{67}$ La Guía de aplicación de la Ley para el profesional sanitario (p. 33) observa «el papel crítico que juega la familia» en este proceso. Según los estudios disponibles, en el $80 \%$ de los casos la familia conoce la petición del paciente y los médicos hablan con la familia en el 73\% de casos (sólo en el $9 \%$ los pacientes no se lo comunicaron a la familia). La Ley reconoce este papel a la familia: recomienda al paciente que se lo comunique al pariente más cercano, así como que no tome la medicación solo (hay una invitación implícita a que lo haga, si fuera posible, en presencia de familiares y amigos) y, por último, uno de los dos testigos (no los dos) puede ser un familiar. 
de que haya otra persona presente cuando tome la mediación letal y de no hacerlo en un lugar público ${ }^{68}$; informar al paciente de que tiene la oportunidad de rescindir la solicitud en cualquier momento; verificar, inmediatamente antes de escribir la prescripción letal, que el paciente está adoptando una decisión informa$\mathrm{da}$; rellenar la información médica requerid $\mathrm{a}^{69}$; asegurarse de que se sigue el procedimiento legalmente prescrito antes de proporcionar la medicación letal; dispensar medicamentos directamente, incluyendo aquellos auxiliares que minimicen las incomodidades del paciente (si está autorizado para ello). El médico ordinario extenderá después el certificado de muerte de su paciente.

Un segundo médico deberá, como se ha indicado, examinar al paciente y confirmar, por escrito, el diagnóstico del médico ordinario de que el paciente sufre una enfermedad terminal, así como verificar que es competente, que actúa voluntariamente y ha adoptado una decisión informada (127.820\$3.02).

El paciente deberá realizar inicialmente una petición oral y otra escrita ante el médico que le atienda ordinariamente y reiterar la petición oral ante el mismo médico no menos de 15 días después de la primera. En ese momento de la segunda petición oral, el médico ordinario deberá ofrecer al paciente la oportunidad de rescindir la solicitud (127.840\$3.06); si no lo hiciera, no podría prescribir la medicación letal (127845\$3.07). La Ley establece un "periodo de espera» de no menos de 15 días desde la petición oral inicial del paciente y el escrito de prescripción de la medicina letal. Del mismo modo, deberán transcurrir, al menos, 48 horas entre la petición por escrito del paciente y la receta de la medicina (127.850\$3.08). El paciente puede revocar su petición en cualquier tiempo y de cualquier manera sin prestar atención a su estado mental (127.845\$3.07).

La Ley afirma enfáticamente que de ningún modo autoriza a ningún médico o a cualquier otra persona a poner fin a la vida de un paciente por medio de una inyección letal, homicidio por compasión o eutanasia activa. Las acciones que permite la norma no constituirán suicidio, suicidio asistido, homicidio

${ }^{68} \mathrm{Si}$, pese a todo, lo hiciera, los gastos derivados de ello permitirán a la entidad pública que los haya asumido una demanda contra los bienes de la persona fallecida (127.892).

${ }^{69}$ La Ley exige documentar en el Informe médico del paciente: todas las solicitudes orales y escritas de medicación letal formuladas por el paciente; el diagnóstico y pronóstico del médico ordinario, la determinación de que el paciente es competente, actúa voluntariamente y ha adoptado una decisión informada; el diagnóstico y pronóstico del segundo médico y la verificación de los extremos anteriores; si hubo derivación al psiquiatra, un informe de los resultados y determinaciones; la oferta del médico ordinario de rescindir su solicitud al final del procedimiento; y una nota del médico ordinario indicando que todas las exigencias de la Ley se han seguido, indicando los pasos dados, incluyendo qué tipo de medicación se prescribió (127.855\$3.09). 
por compasión u homicidio (127.880\$3.14). Ninguna persona responderá civil o penalmente, o se someterá a responsabilidad profesional disciplinaria por participar de buena fe de acuerdo con la Ley. Ninguna organización profesional, o asociación, o proveedor de servicios para la salud podría someter a nadie a censura, disciplina, suspensión, pérdida de licencia o privilegios o cualquier otra sanción por participar o rehusar participar de buena fe en el procedimiento previsto por la Ley. Se reconoce expresamente un derecho de objeción de conciencia: ningún profesional de la salud podrá ser obligado, por ley o contrato, a participar en la provisión de medicación que ponga fin a la vida de un paciente de una manera humana y digna ${ }^{70}(127.885 \$ 4.01)$. Por otro lado, el personal sanitario cometerá delito si altera o falsifica la petición de medicación letal, o destruye u oculta la rescisión de esa petición o si coarta o ejerce influencia indebida sobre el paciente para que solicite la medicación, además de las responsabilidades civiles por daños a los que tenga que hacer frente, en su caso, por conductas negligentes o intencionadamente contrarias a lo dispuesto por la Ley (127.890\$4.02).

Éste es, pues, el contenido de la Ley de Muerte con Dignidad del Estado de Oregón. Como ha quedado de manifiesto, son numerosas las garantías procedimentales para asegurar el consentimiento, libre y actual, de la decisión del paciente: $\left(1 .^{\mathrm{a}}\right)$ Este tipo de muerte se reserva únicamente para adultos competentes que sean enfermos terminales. No está disponible para otros supuestos, como el de una enfermedad grave y crónica que produzca padecimientos, pero no la muerte. Y no autoriza la aplicación de la eutanasia o cualquier forma de homicidio a petición. En todos los casos es el propio paciente quien se auto-administra por vía oral la medicación letal. (2.a) El paciente debe formular la petición de forma oral dos veces y escrita una vez, después de ser informado exhaustivamente de todo lo relativo a su enfermedad (diagnóstico, pronóstico, riesgos asociados a la medicación que se le prescriba, resultado probable de la misma, alternativas factibles, incluyendo control del dolor, cuidados terminales, etc.). Puede desistir en cualquier momento y se establecen ciertos plazos de espera para evitar decisiones precipitadas. (3. $\left.{ }^{a}\right)$ La norma pretende, así mismo, evitar ser aplicada en casos de depresión o cualquier otro desorden de tipo psicológico del paciente. $\left(4 .^{\mathrm{a}}\right)$ Se exige la participación de dos médicos (tres en el caso de que el paciente requiera previo tratamiento psicológico). (5. ${ }^{\mathrm{a}}$ Intervienen

${ }^{70}$ La Guía para el personal sanitario de aplicación de la Ley de Muerte con Dignidad invita a los médicos a «explorar sus propias actitudes acerca del sufrimiento", ya que algunos pueden considerar que tiene sentido y otros que no, lo cual impactaría en todo caso en su relación con los pacientes. Por ello, afirma la Guía (p. 9), debe permitirse a los médicos que elijan libremente participar o no en un suicidio asistido. 
también dos testigos en la petición escrita. El resultado, hasta el momento, es que el número de pacientes que solicitan el barbitúrico es «bajo y estable $\mathrm{e}^{71}$ ».

La aplicación de la Ley confirma este intento de prudencia y equilibrio en la intervención de los médicos y de aseguramiento de la voluntariedad de la decisión de suicidio por parte del paciente. La Ley ordena al Departament of Human Services hacer el seguimiento estadístico anual y público de su aplicación (con la reserva de los datos personales, por supuesto: 127.865\$3.11). De hecho, esta información está disponible en la página web correspondiente ${ }^{72}$. ¿Cuáles son los resultados? El último Informe anual que se dispone es el octavo, de 9 de marzo de 2006. El número de prescripciones letales y de muertes por ellas ha sido el siguiente. En 1998, se prescribieron 24 y 16 residentes en Oregón las injirieron y murieron; en 1999, 33 prescripciones y 27 muertes; en 2000, 39 prescripciones y 27 muertes; en 2001, 44 prescripciones y 21 muertes; en 2002, 58 prescripciones y 38 muertes; en 2003, 68 prescripciones y 42 muertes; en 2004, 60 prescripciones y 37 muertes; en 2005, 64 prescripciones y 32 muertes. Así pues, en ocho años de aplicación de la Ley, se han suicidado siguiendo el procedimiento previsto en ella 240 personas (lo que arroja una media de 30 enfermos terminales al año). Como el propio Informe constata, nada que ver con las enormes cifras de la eutanasia en Holanda. Después de un incremento inicial de suicidios asistidos durante los primeros cinco años de aplicación, el número de personas que recurren a este procedimiento permanece relativamente estable desde 2002. Para valorar correctamente estas cifras, hay que añadir las que miden el total de fallecimientos (en ese mismo periodo de tiempo, 74.967) Pues bien, en 1998 hubo 5,5 muertes por suicidio asistido en Oregón por cada 10.000 muertes, 9,2 en 1999, 9,1 en 2000, 7,1 en 2001, 12.2 en 2002, 13,6 en 2003, 12,3 en 2004 y 12,1 en 2005 (de media, una muerte por suicidio asistido de cada 800 fallecimientos en Oregón). Según el Informe de 2005, respecto del resto de fallecidos en Oregón, los enfermos que más han utilizado el suicidio asistido han sido personas no demasiado mayores (con una media de edad de 70 años frente a la de 78 general), con un tumor maligno (84\% frente al $24 \%$ —otras enfermedades presentes significativamente han sido la esclerosis lateral amiotrófica y el SIDA-) y mayor formación (el $37 \%$, frente al $15 \%$ general tenían el grado de bachiller). Hay mayor prevalencia entre divorciados y solteros que entre casados y viudos ${ }^{73}$. Menos seis asiáticos y un

${ }^{71}$ LINDSAY, ob. cit., p. 101.

$72 \mathrm{http} / / /$ www.oregon.gov/DHS/ph/pas/index.shtml (consultada por última vez: 9 de marzo de 2007)

73 De cada 10.000 fallecidos en Oregón, 58,7 que han recurrido al suicidio asistido son divorciados, 53,1 solteros, 30,5 casados y 22,3 viudos. 
negro, todos los que han acudido al suicidio asistido han sido blancos. Sin embargo, los sexos están bastante igualados: 53\% hombres, $47 \%$ mujeres.

Los médicos indicaron que la motivación de los pacientes para solicitar la medicación era muy variada, pero las causas más mencionadas en 2005 fueron una capacidad decreciente en llevar a cabo actividades que hacen la vida más agradable (89\%), pérdida de dignidad (89\%) y de autonomía (79\%). Se produjeron complicaciones en tres casos: dos de regurgitación de la medicación y un tercero de un paciente que recobró la consciencia después de tomarla, 65 horas después (a esta persona no se le prescribió una segunda medicación y murió 14 días después de la enfermedad subyacente). El 50\% de los pacientes perdió la consciencia dentro de los cinco primeros minutos tras la ingesta de la medicación letal (un paciente tardó en perderla 9,5 horas), y el mismo porcentaje falleció antes de 26 minutos. Menos dos, todos murieron en casa; todos tenían alguna forma de seguro de salud; el $92 \%$ estaban apuntados en el sistema de cuidados denominado hospice care, un programa de importancia fundamental en el sistema de suicidio asistido de Oregón ${ }^{74}$. La media de duración de relaciones del paciente con su médico fue de ocho semanas ${ }^{75}$. La mayoría de los médicos que atienden ordinariamente a los pacientes que han decidido suicidarse de forma asistida son médicos de familia $\left(62 \%{ }^{76}\right)$; hay también oncólogos $(23 \%)$ e internistas (10\%). La medicación empleada desde 1998 hasta la actualidad han sido barbitúricos: en el 56\% de los casos pentobarbital, en el 43\%, sercobarbital.

La valoración de estos datos está sujeta, obviamente, a controversia. La Guía de aplicación de la Ley de Muerte con Dignidad para profesionales sanitarios, junto con muchas otras propuestas de mejora, señala dos que me parecen de importancia crucial. Una se refiere a la «fuerte» recomendación de que se derive a la consulta psicológica o psiquiátrica a todos los pacientes que soliciten el

${ }^{74}$ Se trata de una serie de servicios ofrecidos por un equipo interdisciplinar (médico, director médico del programa, enfermero, trabajador social e incluso consejero espiritual de propia elección) para cubrir los diversos tipos de necesidades que tiene un enfermo terminal en los momentos más próximos a su muerte. El programa incluye cuidados paliativos (alivio del dolor y control de síntomas), pero también de otro tipo (sociales, espirituales, etc.) para el enfermo y su familia, que participa en la implementación del plan de cuidados. Los pacientes tienen acceso al personal del hospice 24 horas al día, 7 días a la semana, por teléfono o visita domiciliaria. Más del $95 \%$ de los cuidados se dispensan en el domicilio del paciente o su lugar de residencia. La inmensa mayoría de los pacientes que se suicidan de acuerdo con la Ley de Muerte con Dignidad participan en este programa. La estancia media en él fue de 16 días en 2003. Ver: Guía para los profesionales sanitarios, pp. 17 y ss.

75 Lo que ha sido criticado (GoRsuCH, ob. cit., p. 1347) por considerarlo un tiempo insuficiente para una evaluación apropiada de la petición de suicidio del paciente.

${ }^{76}$ Los médicos de familia representan tan sólo el 15\% de todos los médicos de Oregón. 
suicidio asistido y no sólo a aquéllos de los que el médico ordinario aprecie síntomas de depresión o desorden mental ${ }^{77}$. La tendencia de derivación al psiquiatra ha sido, además, descendente (más del $30 \%$ en los primeros años, menos del $15 \%$ en los últimos); y parece que la relación con el psiquiatra es extraordinariamente corta, reduciéndose a una sola visita ${ }^{78}$. La otra alude al hecho de que en Estados Unidos no todos los ciudadanos tienen seguro médico o uno que les permite afrontar los gastos de este proceso. Por ello, la Guía recomienda explorar cualquier prueba de que factores económicos subyacen en el interés del paciente por el suicidio asistido para abortar el proceso $^{79}$.

Autores críticos de la Ley ${ }^{80}$ apuntan la idea de que muchas de las prescripciones médicas parecen ser dispensadas por un pequeño pero activo grupo de médicos apoyado por asociaciones pro-eutanásicas. Lo cierto es, sin embargo, que la objeción al suicidio asistido que podríamos denominar "anti-democrática», esto es, la que estima que su implantación se debe no a los deseos de la mayoría de la población, sino a la imposición de una minoría activa, pero poderosa social y mediáticamente (que es la que, entiendo, podría subyacer en el argumento mencionado), no cabe de ninguna manera en Oregón, donde el sistema ha sido validado por el cuerpo electoral no una vez, sino dos, y la segunda de modo aún más rotundo que la primera. Son los ciudadanos de Oregón los que han aprobado y defendido el modelo legal de suicidio asistido y los que, a la vista de los datos que se conocen, acuden a él libremente, sin que la militancia ideológica de un grupo de médicos y otros profesionales a favor del modelo llegue a producir cualquier tipo de manipulación o adulteración del mismo ${ }^{81}$. Aunque la presencia significativa de grupos de presión a favor o en contra de la eutanasia o del suicidio asistido es una variable que siempre debe ser considerada para explicar su regulación legal en un ordenamiento determinado (como vimos, fue muy importante en el origen del establecimiento del sistema legal de Oregón), creo que por sí sola no es un factor tan determinante y, en todo caso,

77 Cit., p. 63. Gorsuch (ob. cit., p. 1347) añade que no es razonable que la derivación al psiquiatra corresponda a médicos que no están especializados en diagnóstico de desórdenes mentales.

${ }^{78}$ Gorsuch, ob. cit., p. 1380.

79 Cit., p. 83.

${ }^{80}$ Gorsuch, The Future of Assisted Suicide and Eutanasia. Princenton University Press, Princenton \& Oxford, 2006, pp. 119 y ss.

${ }^{81}$ Bien es cierto que la información que se difunde de la aplicación de la Ley en Oregón es incompleta y no relaciona (en principio, por protección de los datos de los médicos) el número de doctores que han prescrito drogas letales en diversos años y el número de las que prescriben por año (STEVENS, ob. cit., p. 200). Pero no está demostrado que algunos médicos estén presionando a los pacientes para suicidarse de modo asistido, sino, a lo sumo, de lo contrario, de la presión de algunos pacientes hacia sus médicos. 
no me parece que puede argüirse para deslegitimar el modelo. Y menos en Oregón, por las razones mencionadas. Otra cosa es que se llegara a demostrar que uno o varios médicos inducen a algunos de sus pacientes a optar por el suicidio asistido; esto, obviamente, está prohibido por la Ley. Ciertamente, los médicos deben informar de sus actividades sólo después de que el paciente ya haya fallecido, de modo que no cabe revisar su responsabilidad cuando ya es demasiado tarde para prevenir cualquier error o abuso.

Otras objeciones que se han formulado identificando puntos débiles de las garantías procedimentales de la Ley de Muerte con Dignidad son las siguientes ${ }^{82}$. El segundo médico se elige a sugerencia del primero, con lo que no se garantiza un juicio «imparcial» de la solicitud del paciente. Tampoco exige la Ley que este segundo médico sea especialista; esto es incoherente con el hecho de que más de tres de cada cuatro enfermos padece algún tipo de tumor y, sin embargo, hay casi tres veces más de médicos de familia que oncólogos participando a lo largo del proceso. La Ley tampoco exige que el médico esté presente cuando el paciente procede a suicidarse, de modo que no hay garantía de que comprueben la condición mental de éste en el momento de la muerte ${ }^{83}$. La competencia del enfermo se decide sólo en el momento en el que formula la solicitud del suicidio asistido, que debe ser quince días antes, como mínimo, del momento en el que efectivamente lo lleve a cabo, pero que puede producirse con varias semanas más, e incluso con meses, de antelación. La ausencia del médico en el momento de la muerte también impide que se obtenga información de las complicaciones que, en su caso, pudieran surgir en esa situación.

Algunas ideas de la experiencia de Oregón podrían, quizás retenerse en orden a valorar una eventual despenalización de la eutanasia o del suicidio asistido en España.

(1. a) La primera es que el sistema legal implantado en Oregón, aún siendo mejorable, parece asegurar mejor la protección contra cualquier tipo de abuso, error o presión sobre el paciente que decide suicidarse, lo que no sucede en aquellos países donde es la eutanasia la que se halla despenalizada. En contra de lo que sostienen algunos autores ${ }^{84}$, suicidio asistido y eutanasia son dos figuras dis-

${ }^{82}$ Ver: GoRSUCH, 2004, ob. cit., pp. 1372 y ss. A su juicio (1375), «no está claro si, y en qué medida, el experimento de Oregón, al menos tal y como está estructurado en la actualidad, será capaz de servir como modelo para otros Estados».

${ }^{83}$ Entre 1998 y 2002 los médicos sólo estuvieron presentes en el 33\% de las ocasiones (GORSUCH, ibidem, p. 1374).

${ }^{84}$ Por ejemplo, Gorsuch $(2004,1352)$, para quien «no hay ninguna razón moral o práctica para distinguir entre suicidio asistido y eutanasia». El modelo de Oregón no es para él más que 
tintas: es un dato de derecho positivo ${ }^{85}$, pero además de gran importancia práctica, basta ver, por ejemplo, el número de eutanasias que se producen al año en Holanda, por ejemplo, y el número de suicidios asistidos al que se llega en Oregón.

$\left(2 .^{a}\right)$ Como demuestran los Informes anuales sobre la aplicación de la Ley y la Guía para los profesionales sanitarios, el dolor físico incontrolado, en contra de lo que suele creerse, no está entre las motivaciones principales de los pacientes para acudir al suicidio asistido (sólo uno de cada cuatro lo alega). El malestar psicológico y existencial es un factor de motivación más importante; son elementos a considerar, por ejemplo, la desesperanza, las pérdidas no resueltas de familiares, la percepción de falta de apoyo en el entorno ${ }^{86}$, la pobre calidad de vida, el deseo de controlar las circunstancias de la propia muerte, la pérdida de autonomía, etc. Los estudios sugieren que las razones que mueven a una persona a elegir el suicidio asistido son complejas y no responden sólo a la necesidad de un control de síntomas. Este hecho cuestiona en gran medida la idea, al menos en su formulación más radical, de que simplemente por aumentar y mejorar el sistema de cuidados paliativos decrecería de modo directamente proporcional el deseo de los pacientes terminales o con graves padecimientos de poner fin a su vida directamente o con ayuda de terceros.

(3. $\left.{ }^{a}\right)$ Un sistema que permite el suicidio asistido, incluso aunque, a diferencia de otro que despenalice la eutanasia asegura mejor la voluntariedad de la decisión del paciente, arroja nuevas y muy críticas responsabilidades y dificultades a las funciones del personal sanitario. Se produce un cambio cualitativo en el ámbito de tales funciones. Así lo pone de manifiesto la Guía de aplicación de la Ley de Muerte con Dignidad para profesionales sanitarios ${ }^{87}$ y algún trabajo en particular ${ }^{88}$. Médicos y enfermeros se enfrentan a la dificultad de decidir si participan o no en un suicidio asistido. Si deciden hacerlo, esto supone desafiar uno de los principios más tradicionales y poderosos de su formación, el de que

una «decisión táctica» para luchar de modo gradual a favor de la eutanasia, que sería el paso deseable y buscado final. Sobre este tema volveremos más adelante. Tan sólo indicaré por el momento que el propio GORSUCH se ve obligado a reconocer que la legislación de Oregón es «ciertamente más refinada» que la holandesa.

85 En este sentido también GRANT y LinTON («Relief or Reproach?: Eutanasia, Rights in the Wake of Measure 16», en Oregon Law Review, vol. 74, 1995, p. 462).

${ }^{86}$ Es significativa, en este sentido, la mayor prevalencia de divorciados y solteros entre los que deciden recurrir al suicidio asistido, lo que permite deducir a GORSUCH $(2004,1378)$ que el mayor aislamiento social o la depresión podrían conducir a la decisión de buscar la muerte.

${ }^{87}$ Cit., pp. 46 y ss.

${ }^{88}$ STEVENS, ob. cit., pp. 192 y ss. 
su función consiste en salvar las vidas de los demás a toda costa; también puede suponer verse en los medios de comunicación en el contexto de un asunto sobre el que no existe consenso social; por no hablar de la larga inversión de tiempo y del enorme coste emocional que implica acompañar el proceso de suicidio de una persona ${ }^{89}$, de las complicaciones de carácter técnico que pueden surgir (aunque no es lo habitual, algunas sí se producen con la ingesta: regurgitaciones, tiempo prolongado de vida después de la ingesta del barbitúrico, etc., pero también en otras fases: dificultad para conseguir la segunda opinión médica, fallos de coordinación con el personal del programa de hospice, etc. ${ }^{90}$ ), o de las responsabilidades (civiles e incluso penales) en que pueden incurrir si incumplen algunas de las numerosas y detalladas exigencias legales. El dato a retener, en todo caso, es que estos significativos efectos colaterales sobre el personal sanitario que participa en los suicidios asistidos (y no digamos la eutanasia) deben ser tenidos en cuenta cuando se discutan los pros y contras de una eventual despenalización.

(4. $\left.{ }^{a}\right)$ Puede ser interesante también retener que un sector de la literatura penalista española especializada considera que el tipo de cooperación al suicidio que se permite en Oregón, al no ser necesaria, pues el paciente tendrá a su disposición otros medios para quitarse la vida, sería una conducta ya impune en nuestro ordenamiento, que además, ni siquiera exige que quien presta la ayuda sea médico, ni ningún otro requisito ${ }^{91}$. Encuentro discutible esta tesis.

\section{GARANTÍAS PROCEDIMENTALES QUE PUEDEN EXTRAERSE DE LA EXPERIENCIA COMPARADA}

Marginado en este estudio (no así en una monografía de próxima aparición) el debate de fondo sobre el estatuto constitucional de eutanasia y suicidio asistido, en el supuesto de que una futura mayoría parlamentaria decidiera en Es-

89 Significativamente, el primer Informe anual, el de 1998, sí informaba del impacto emocional sobre el personal sanitario de la aplicación de la Ley, pero este extremo se ha omitido en los informes posteriores (ver: STEVENS, ob. cit., p. 192). El Select Comité on the Assisted Dying for Terminally Ill Hill de la Cámara de los Lores británica relató algunos casos de «trauma emocional» de varios médicos de Oregón. Sin embargo, es decreciente el número de médicos que está presente en el momento en que el enfermo ingiere la prescripción letal.

${ }^{90}$ STEVENS, ibidem, p. 192. Los informes del Gobierno holandés sobre la eutanasia en Holanda también advierten de "complicaciones» en el 7\% de los casos de suicidio asistido y en el 3\% de los de eutanasia (GORSUCH, 2004, p. 1361).

91 Tomás-Valiente, ibidem, p. 17. 
paña introducir alguna forma jurídicamente lícita de suicidio asistido y/o eutanasia, me parece que necesariamente también debiera introducir determinadas garantías para evitar abusos contra el derecho fundamental de protección jurídica de la vida (art. $15 \mathrm{CE}$ ). A mi juicio, suicidio asistido y/o eutanasia deben considerarse, desde el punto de vista jurídico-constitucional, como eventuales límites o excepciones válidas (bajo ciertas condiciones y siempre que se rodeen de las garantías precisas) del «derecho a la vida», más que «ordinarios» ejercicios de algún derecho fundamental (con independencia de que se intente fundar en la dignidad, el libre desarrollo de la personalidad, la integridad personal, la libertad ideológica o religiosa, la intimidad personal, etc. $\left.{ }^{92}\right)$ o, incluso, de la libertad general del art. 1.1 de la Constitución (o del libre desarrollo de la personalidad del art. 10.1 CE).

De los modelos extranjeros analizados puede extraerse el marco de garantías de procedimiento dirigidas a asegurar la libertad del consentimiento del enfermo que se someta, en esa hipótesis despenalizadora, a eutanasia o suicidio asistido y su protección frente a eventuales abusos. Este marco podría resultar útil si el legislador español decidiera en el futuro legalizar la eutanasia. F. Hufen ha sostenido que «cuanto más difíciles son las soluciones de los conflictos de derechos fundamentales, tanto más importante se hace la protección de los derechos fundamentales a través de garantías de procedimiento ${ }^{93}$ ". Además de modificar el vigente art. 143.4 del Código Penal para validar tales conductas, debería dictarse una ley específica (de rango orgánico, en mi opinión) que contuviera tales garantías. El marco máximo de garantías, mayor incluso que el que ofrece Oregón (el sistema más garantista; obviamente donde existe menos protección es en Holanda y esto encuentra reflejo inmediato en la alta cifra de eutanasias y suicidios asistidos que allí se producen), podría diseñarse del siguiente modo:

$\left.1 .^{\circ}\right)$ En orden a garantizar con la mayor intensidad posible el libre consentimiento del enfermo, es claramente preferible elegir la solución del suicidio asistido que la de la eutanasia. La experiencia de Oregón demuestra que este sistema evita, en gran medida, los riesgos de la pendiente resbaladiza que sí se producen, en mayor (Holanda) o menor (Bélgica) medida, en los países donde se permite la eutanasia. De modo que si el legislador español algún día optara por legalizar la ayuda a morir (constitucionalmente no está, por lo demás, obligado a hacer-

92 En la monografía Eutanasia, suicidio asistido y derechos fundamentales, pendiente de publicación.

93 Ibidem, p. 857. En sentido similar, LANDAU: «Heiligkeit des Lebens und Selbstbestimmung im Sterben», en Zeitschrift für Rechtspolitik, 2005, p. 54. 
lo, aunque sí podría, bajo ciertas condiciones), me inclino a sugerir que sería mejor que se inspirara en el modelo de Oregón y no en el de Holanda.

$\left.2 .^{\circ}\right)$ En cuanto a las personas que podrían pedir la eutanasia y/o el suicidio asistido, lo más sensato es que fueran mayores de 18 años (la extensión del derecho de consentimiento informado de los menores a este campo sería verdaderamente problemático), competentes y residentes en España (para evitar el turismo eutanásico, que no se ha evitado, por ejemplo, en relación con el aborto). En cualquier momento y de cualquier forma deberían poder revocar su petición. Han de ser enfermos terminales (sería deseable que se definiera desde el punto de vista médico que ha de entenderse por «terminal»). La admisión de una enfermedad no mortal pero grave, crónica y con padecimientos difíciles de soportar también podría hacerse, pero, naturalmente, con mayores cautelas, sobre todo si el sufrimiento es de carácter psicológico o moral. Esta hipótesis podría convertirse en una fuente de fraudes a la ley (más o menos tolerados, porque no es fácil establecer un control previo).

3. $\left.{ }^{\circ}\right)$ Respecto de las personas que asistirían en la eutanasia y/o el suicidio asistido, la regulación debería exigir, por supuesto, que fueran médicos y que se produjera, además, una doble consulta médica: la del médico que asiste ordinariamente al paciente y la de otro médico, independiente del primero y especialista en la enfermedad del paciente (e, incluso, una tercera consulta de corte psicológico o psiquiátrico para certificar que el enfermo no sufre ningún desorden de este tipo y/o depresión). Los médicos tendrían obligación (exquisita en este caso) de observar los requerimientos del consentimiento informado, de comprobar la firme voluntad del paciente y de que la enfermedad es de las que legitiman la práctica de la eutanasia y/o el suicidio asistido ${ }^{94}$, así como de documentar e informar al órgano administrativo de control (y al judicial, en su caso) de que se han seguido estrictamente todos los pasos previstos legalmente. Me parece que si se optara por el «modelo Oregón», a diferencia de lo que allí ocurre, algún médico de los que asisten al enfermo debería estar presente en el momento en que éste ingiere la sustancia fatal (por si surgieran complicaciones técnicas ${ }^{95}$. La Ley debería también permitir la objeción de conciencia del personal sanitario que atiende al enfermo en este trance.

${ }^{94}$ Una enfermedad terminal (incurable y avanzada) o una patología incurable que provocara un sufrimiento severo y permanente al sujeto (Informe del Comité Consultivo de Bioética de Cataluña, de 2006).

95 El Informe del Comité Consultivo de Bioética de Cataluña requiere la presencia médica en el momento de la muerte y que se aplique un método «seguro, rápido y que no añada padecimiento». 
$\left.4 .^{\circ}\right)$ Por lo que se refiere al procedimiento, éste debería abrirse mediante una petición escrita del paciente, firmada ante testigos (algunos de ellos sin vínculos afectivos y, sobre todo, económicos con el enfermo). Sería interesante que se estableciera un plazo de espera desde que se solicita la eutanasia y/o el suicidio asistido hasta una segunda decisión de confirmación ante el médico ordinario, así como (aunque fuera menor, según ocurre en Oregón y también sucedía en la breve experiencia australiana) desde esta segunda decisión de confirmación hasta el momento de llevar a cabo el suicidio o la eutanasia. Esto presupone que el enfermo sea consciente tanto cuando solicita la eutanasia y/o el suicidio asistido cuanto en el momento de su administración. Un enfermo terminal inconsciente tiene la posibilidad, a través del procedimiento previsto en la Ley $41 / 2002$, de acceder a medidas de limitación del esfuerzo terapéutico y, en este sentido, el documento de instrucciones previas puede desempeñar un valioso, e incluso determinante, papel.

5..$\left.^{\circ}\right)$ Necesariamente habría de arbitrarse un control a posteriori, mediante la comprobación por parte de un organismo público/administrativo a crear, de que se han observado todas las condiciones y requisitos legales ${ }^{96}$. Por supuesto, este órgano deberá elevar a la autoridad judicial (a través del ministerio fiscal) el examen de cualquier irregularidad que pudiera encontrar en su enjuiciamiento. Pudiera plantearse también la posibilidad de arbitrar un procedimiento de control previo, quizás ejercido por los Comités de Ética asistencial, que podrían comprobar, justo antes de la administración de la eutanasia y/o el suicidio asistido, que se han cumplido todos los requisitos legales. Esto podría ser especialmente interesante para el caso de enfermos con afecciones irreversibles pero no terminales, como sugiere el Informe del Comité Consultivo de Bioética de Cataluña ${ }^{97}$. El Ministerio de Sanidad debería publicar cada año un Informe donde se recogieran todos los datos relativos a la eutanasia y/o el suicidio asistido en España que permitiera una total transparencia y una permanente valoración social y política a efectos de introducir eventuales ajustes.

${ }^{96}$ El Informe del Comité Consultivo de Bioética de Cataluña se pronuncia claramente a favor en este punto de un modelo inspirado en el sistema holandés.

${ }^{97}$ El Informe del Comité Consultivo de Bioética de Cataluña, de 2006, al analizar las posibilidades de control de la eutanasia y/o del suicidio asistido, argumenta que el control puede ser $e x$ ante (autorización previa de algún órgano, que daría seguridad a la ciudadanía y garantizaría la legalidad, pero burocratizaría el proceso - e incluso podría dar lugar a autorizaciones tardías, posteriores al fallecimiento del enfermo) o ex post (al estilo holandés, por ejemplo) y se inclina por este último para los enfermos terminales, pero a favor del primero para el supuesto de enfermos con afecciones irreversibles pero no terminales. 


\title{
Title
}

The debate of the euthanasia and the doctor-assisted suicide in compared perspective. Procedure guarantees to keep in mind in front of their possible future decriminalization in Spain

\section{Resumen}

En este trabajo se examina la regulación jurídica de la eutanasia y del suicidio asistido por médico en diversos ordenamientos donde se permiten bajo ciertas condiciones. Concretamente, se estudian las experiencias de despenalización parcial de la eutanasia de Holanda y Bélgica y el procedimiento de suicidio asistido disponible en el Estado norteamericano de Oregón. De esta «mirada por encima de las fronteras» se extraen algunas de las garantías que una eventual y futura despenalización del suicidio asistido y/o de la eutanasia en España debiera contemplar para garantizar el libre consentimiento del sujeto».

\begin{abstract}
This paper examines the legal regulation of euthanasia and doctor-assisted suicide in various jurisdictions where permitted under certain conditions. Specifically, we examine the experiences of partial decriminalization of euthanasia in the Netherlands and Belgium and the procedure of assisted suicide available in the American state of Oregon. This «look beyond the borders» draws some of the guarantees and a possible future decriminalization of assisted suicide and / or euthanasia in Spain should look to ensure the free consent of the subject.
\end{abstract}

\section{Palabras clave}

Eutanasia, suicidio asistido, protección jurídica de la vida

\section{Key words}

Euthanasia, doctor-assisted suicide, right to life 